LA-13990-SR

Status Report

Approved for public release;

distribution is unlimited.

Emissions Inventory Report Summary:

Reporting Requirements for the

New Mexico Administrative Code,

Title 20, Chapter 2, Part 73

(20 NMAC 2.73) for Calendar Year 2001 
Previous reports in this unclassified series are LA-13630-SR, LA-13728-SR, and LA-13850-SR.

Los Alamos National Laboratory, an affirmative action/equal opportunity employer, is operated by the University of California for the United States Department of Energy under contract W-7405-ENG-36.

This report was prepared as an account of work sponsored by an agency of the United States Government. Neither the Regents of the University of California, the United States Government nor any agency thereof, nor any of their employees make any warranty, express or implied, or assume any legal liability or responsibility for the accuracy, completeness, or usefulness of any information, apparatus, product, or process disclosed, or represent that its use would not infringe privately owned rights. Reference herein to any specific commercial product, process, or service by trade name, trademark, manufacturer, or otherwise does not necessarily constitute or imply its endorsement, recommendation, or favoring by the Regents of the University of California, the United States Government, or any agency thereof. The views and opinions of authors expressed herein do not necessarily state or reflect those of the Regents of the University of California, the United States Government, or any agency thereof. Los Alamos National Laboratory strongly supports academic freedom and a researcher's right to publish; as an institution, however, the Laboratory does not endorse the viewpoint of a publication or guarantee its technical correctness. 
LA-13990-SR

Status Report

Issued: April 2003

Emissions Inventory Report Summary:

Reporting Requirements for the

New Mexico Administrative Code,

Title 20, Chapter 2, Part 73

(20 NMAC 2.73) for Calendar Year 2001

Risk Reduction Environmental Stewardship Division,

Meteorology and Air Quality Group (RRES-MAQ) 



\section{Table of Contents}

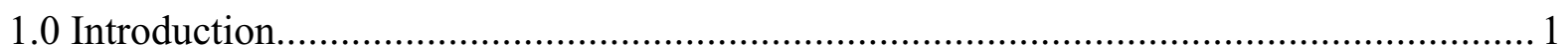

2.0 Emissions-Inventory Reporting Requirements ......................................................... 2

3.0 Content of the Emissions Inventory Report ………................................................ 2

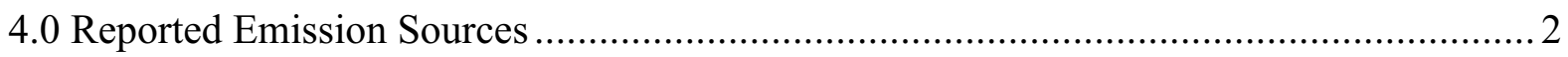

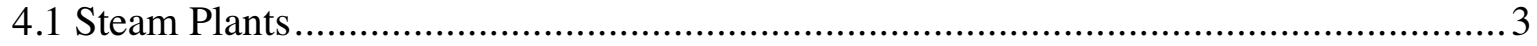

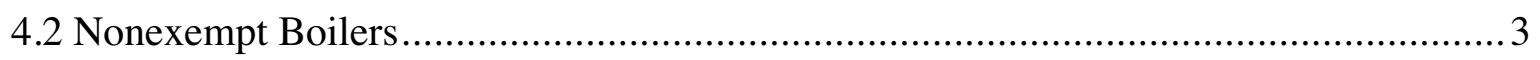

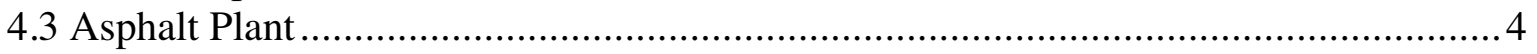

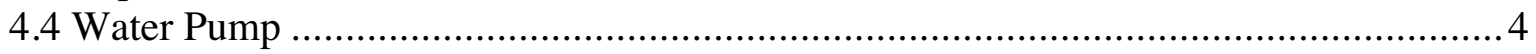

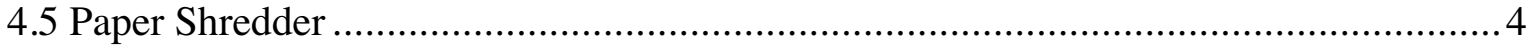

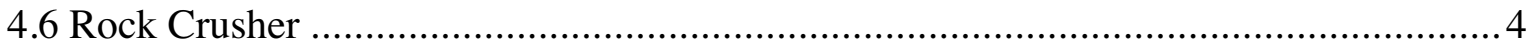

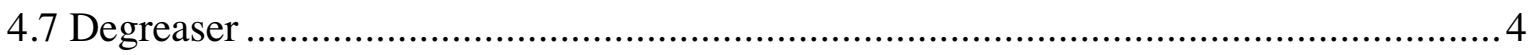

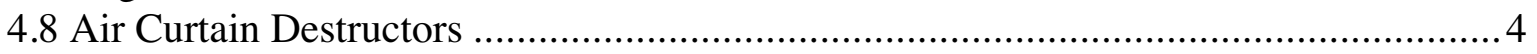

4.9 Emissions from Research and Development Activities .......................................... 5

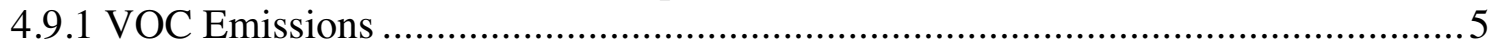

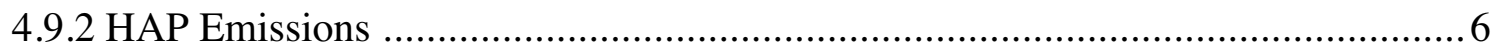

4.10 Permitted Beryllium-Machining Operations ......................................................

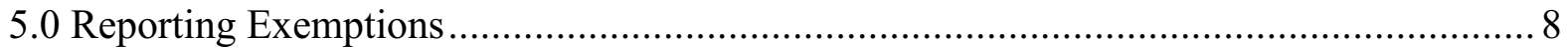

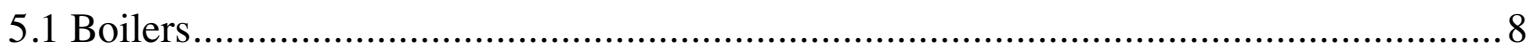

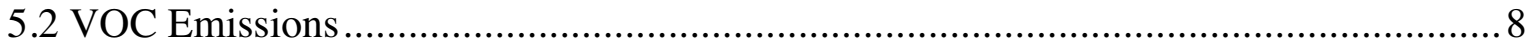

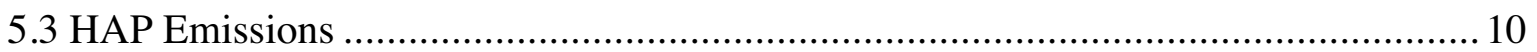

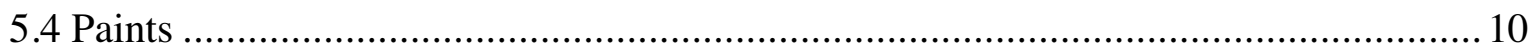

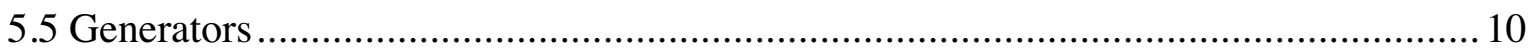

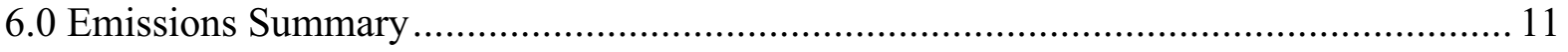

Attachment A. Emissions Inventory Summary ......................................................... 15

Attachment B. Emission Calculation Worksheets for Individual Emission Units ....... 16

Attachment C. Emissions Inventory Submittal to NMED .........................................22 



\title{
Emissions Inventory Report Summary: Reporting Requirements for the New Mexico Administrative Code, Title 20, Chapter 2, Part 73 (20 NMAC 2.73) for the Calendar Year 2001
}

by

\author{
Risk Reduction and Environmental Stewardship Division, \\ Meteorology and Air Quality Group (RRES-MAQ)
}

\begin{abstract}
Los Alamos National Laboratory is subject to annual emissions-reporting requirements for regulated air contaminants under Title 20 of the New Mexico Administrative Code, Chapter 2, Part 73 (20.2.73 NMAC), Notice of Intent and Emissions Inventory Requirements. The applicability of the requirements is based on the Laboratory's potential to emit 100 tons per year of suspended particulate matter, nitrogen oxides, carbon monoxide, sulfur oxides, or volatile organic compounds. For calendar year 2001, the Technical Area 3 steam plant was the primary source of criteria air pollutants from the Laboratory, while research and development activities were the primary source of volatile organic compounds. Emissions of beryllium and aluminum were reported for activities permitted under 20.2.72 NMAC. Hazardous air pollutant emissions from chemical use for research and development activities were also reported.
\end{abstract}

\subsection{INTRODUCTION}

Los Alamos National Laboratory (LANL or the Laboratory) has reported on air pollutants generated from its operations since the 1970s when Air Quality Control Regulation 703, Registration of Air Contaminant Sources, was promulgated. According to the regulation, the Laboratory was required to register air pollutant sources that emitted more than $2000 \mathrm{lb}$ per year of any air contaminant. This regulatory requirement later evolved into Title 20 of the New Mexico Administrative Code, Chapter 2, Part 73 (20.2.73 NMAC), "Notice of Intent and Emissions Inventory Requirements." The objective of the reporting requirement is to provide emissions data to the New Mexico Environment Department (NMED) so its staff can determine whether LANL meets state and federal air pollutant standards. 
The Aerometric Information Retrieval System (AIRS) is used to help ensure ambient air quality standards are maintained and to track the state's air pollutant emissions. AIRS (http://www.epa.gov/ttn/chief) is a large air pollution database that contains information, requirements, and data on air pollution and air quality in the United States and various World Health Organization (WHO) member countries. The program is operated by the U.S. Environmental Protection Agency (EPA) and state/local air pollution control agencies. The AIRS database tracks each state's progress towards achieving and maintaining the National Ambient Air Quality Standards (NAAQS) for criteria pollutants. The database is also used as a tool to help improve each state's air quality programs by enabling program members to access and compare past data and view data from other states. For 2001 emissions reporting, NMED imported data from the AIRS database into spreadsheets and requested that LANL update the sheets with the 2001 information.

This annual emissions inventory report includes air contaminant data for total particulate matter (PM), suspended particulate matter in the size range of 10 microns or less $\left(\mathrm{PM}_{10}\right)$, carbon monoxide $(\mathrm{CO})$, nitrogen oxides $\left(\mathrm{NO}_{\mathrm{x}}\right)$, sulfur oxides $\left(\mathrm{SO}_{\mathrm{x}}\right)$, volatile organic compounds (VOCs), beryllium, and aluminum. Additionally, at the request of NMED, this report provides data on hazardous air pollutant (HAP) emissions from chemical use for calendar year (CY) 2001.

\subsection{EMISSIONS-INVENTORY REPORTING REQUIREMENTS}

Annual emissions-inventory reporting requirements under 20.2.73 NMAC apply to any facility that emits or has the potential to emit 5 tons per year or more of lead or lead compounds or 100 tons per year or more of $\mathrm{PM}_{10}, \mathrm{SO}_{x}, \mathrm{NO}_{\mathrm{x}}, \mathrm{CO}$, or VOCs. Emission units that emit in excess of 1 ton of lead per year or 10 tons per year of $\mathrm{PM}, \mathrm{PM}_{10}, \mathrm{SO}_{\mathrm{x}}$, $\mathrm{NO}_{\mathrm{x}}, \mathrm{CO}$, or VOCs must be included in the report to NMED. In addition, emissions from all sources permitted under 20.2.72 NMAC construction permits must be included in the report.

\subsection{CONTENT OF THE EMISSIONS INVENTORY REPORT}

NMED requested that LANL submit emissions data for 2001 via electronic format for entry into AIRS. The information required for submittal includes the following:

- company name, address, and physical location for the facility;

- facility contact information;

- $\quad$ signed certification statement by a responsible facility official; and

- specific information for each emission unit such as the type and efficiency of control equipment, schedule of operation, annual process or fuel combustion rates, and estimated actual emissions for CY 2001.

\subsection{REPORTED EMISSION SOURCES}

The Laboratory's 2001 Emissions Inventory Report includes estimates of actual air emissions for regulated pollutants from the following sources: 
- steam plants,

- nonexempt boilers,

- asphalt plant,

- water pump,

- paper shredder,

- rock crusher,

- degreasers,

- air curtain destructors,

- research and development (R\&D) activities, and

- permitted beryllium-machining operations.

Attachment A includes a summary of emissions from LANL, and Attachment B includes worksheets showing emission calculations for individual emissions sources. In addition to Attachment B, descriptions of the sources listed above are provided in the following subsections of this report. The 2001 Emissions Inventory Report as submitted to NMED is presented in Attachment $\mathrm{C}$.

\subsection{Steam Plants}

The Laboratory operates two steam plants, one located at Technical Area 3 (TA-3) and the other at TA-21. The TA-3 steam plant produces steam for heating and electricity when sufficient power from outside sources is not available. The steam plant at TA-21 provides steam for heating. The heat produced from both steam plants is used for comfort and hot water and to support facility processes. Each steam plant has three boilers that are fueled primarily with natural gas and with diesel fuel as a backup. Actual emissions are estimated on the basis of metered fuel consumption and emission factors. The primary source of emission factors is AP-42, the U.S. Environmental Protection Agency's Compilation of Air Pollutant Emission Factors (Volume 1, Stationary Point and Area Sources, Sections 1 and 3, Fifth Edition). However, emission factors from stack tests conducted at the TA-3 steam plant when it was burning natural gas were also used as appropriate.

\subsection{Nonexempt Boilers}

The Laboratory operates approximately 200 boilers. Most of the boilers are exempt from permitting requirements because of their size and use as comfort boilers and do not need to be included in the emissions inventory. The exemption analysis applied to the boilers is discussed in Section 5.1 of this report.

The nonexempt boilers reported in the 2001 emissions inventory include the following:

- four boilers at TA-16,

- three boilers at TA-48,

- two boilers at TA-53,

- three boilers at TA-55, and

- two boilers at TA-59.

All of the reported boilers burn natural gas. The TA-16 boilers have meters to track the fuel consumption. For all other boilers, the fuel consumption was estimated on the basis of the total natural gas used by the Laboratory minus the amount supplied to the metered sources. Some emission factors were available from stack tests (TA-55), some were 
provided by the boiler manufacturers (Sellers Engineering Company and Kewanee), and the rest were taken from AP-42.

\subsection{Asphalt Plant}

The asphalt plant produces small amounts of asphalt for road repairs in and around the Laboratory. Emissions from the asphalt plant are based on the amount of asphalt produced for the year. The PM emissions from the asphalt plant were calculated with an emission factor obtained from a source test. Otherwise, emission factors from AP-42 were used.

\subsection{Water Pump}

A natural-gas-fired water pump is used to pump potable water from underground wells. Emission factors for $\mathrm{NO}_{x}, \mathrm{CO}$, and VOC emissions were obtained from the pump-engine manufacturer. Otherwise, emission factors from AP-42 were used. The emission factors were used with the metered fuel consumption to estimate actual emissions. Ownership of this water pump was transferred to Los Alamos County in November 2001. Emissions data for the full calendar year 2001 are included in this year's inventory.

\subsection{Paper Shredder}

The shredding operations of the paper shredder at TA-52-11 are a source of PM emissions. Estimates of actual emissions are based on an averaged monthly shredding rate and engineering estimates for controlled emissions. These PM emissions are controlled with a cyclone and a baghouse.

\subsection{Rock Crusher}

In June 1999, the Laboratory was issued a 20.2.72 NMAC construction permit (Permit No. 2195) to operate an impact rock crusher to crush potentially radioactive contaminated concrete removed from buildings as part of the Laboratory's decontamination and decommissioning efforts. The rock crusher was not operated in 2001. Therefore, there were no PM emissions from crushing activities and no combustion products from the crusher's diesel-fired engine for CY 2001.

\subsection{Degreaser}

The halogenated solvent cleaning machine at TA-55 Building PF-4 has a capacity of 18 liters and is registered with NMED's Air Quality Bureau (AQB) as required under the National Emissions Standards for Hazardous Air Pollutants, 40 CFR 63 Subpart T, "Halogenated Solvent Cleaning." The solvent used in the machine, trichloroethylene (Chemical Abstracts Service [CAS] No. 79-01-6), is a VOC and a HAP. Measured losses were reported. LANL has two additional halogenated solvent cleaning machines registered with NMED; however, these two machines did not operate in 2001.

\subsection{Air Curtain Destructors}

In 2001, three air curtain destructors were brought on-site for controlled open burning of wood and wood scrap generated from tree thinning activities at LANL. Both wood burning and engine operation emissions were estimated. Wood burning emissions were estimated based on the total tons of wood burned in 2001 and using emission factors 
presented in the Notice of Intent (NOI) application submitted to NMED in May 2001. Engine emissions were estimated based on the total diesel fuel consumed and the total horsepower hours operated. The estimates used emission factors presented in the NOI application submitted to NMED. The units were operated under an open burn permit issued by NMED's AQB on June 20, 2001.

\subsection{Emissions from Research and Development Activities}

The majority of the Laboratory's work is devoted to research and development (R\&D) activities. Varying operating parameters, as well as amounts and types of chemicals, are used in these activities. R\&D activities occur at virtually all TAs within the Laboratory. $\mathrm{R} \& \mathrm{D}$ activities were evaluated for VOC and HAP emissions and are discussed below.

\subsubsection{VOC Emissions}

With the exception of specific listed chemicals, VOCs are any compounds of carbon that participate in atmospheric photochemical reactions. VOCs include commonly used chemicals such as ethanol, methanol, trichloroethylene, and isopropanol. The Laboratory's Automated Chemical Inventory System (ACIS) CY 2001 data set (chemical containers added to LANL's inventory between January 1, 2001 and December 31, 2002) was reviewed to identify all VOCs from R\&D activities performed at LANL. From this data, certain categories of chemicals were separated and eliminated. The classifications assigned and the corresponding reasons (noted in parentheses) for the separation of chemicals from inventory records are noted below.

- Solid materials (Solids are not a significant source of air emissions based on their low vapor pressure.)

- Non-VOC materials as defined by 40 CFR 51.100100 (Specific chemicals that are listed in 40 CFR 51.100 have been determined to have negligible photochemical reactivity and are therefore exempt.)

- Paints (Paints were evaluated separately-See Section 5.4.)

- Inorganic chemicals (Inorganics are not compounds of carbon.)

- Oils (Oils are not a significant source of air emissions based on their low vapor pressure and are used primarily for maintenance.)

- Fuels used for combustion purposes (Almost all fuels burned in open flame are reduced to $\mathrm{CO}_{2}$ and $\mathrm{H}_{2} \mathrm{O}$ - See Section 5.2.)

Furthermore, the following categories of chemicals were eliminated based on guidance from NMED (see exemptions listed in Table 5.1 for further explanation).

- Container sizes of $1 \mathrm{lb}$ or less,

- Chemicals with vapor pressures less than $10-\mathrm{mm} \mathrm{Hg}$,

- Chemicals used to calibrate equipment,

- Maintenance chemicals,

- Use of office equipment and products,

- Chemicals used for boiler water treatment operations,

- Chemicals used for oxygen scavenging (deaeration) of water, and

- Chemicals used in bench-scale chemical analysis.

\footnotetext{
* This exemption was applied only to biological research solutions. Otherwise, this exemption was not applied. See Table 5.1.
} 
After the elimination of the chemicals and categories of chemicals listed above, the remaining chemical inventory records were assumed to represent VOCs. As a conservative estimate, VOCs identified in the Laboratory's chemical-tracking records were assumed to be $100 \%$ emitted to the air. As a result, the estimated emissions of VOCs at LANL were 18.6 tons. Use of NMED AQB's Operating Permit Program exemptions from the "List of Insignificant Activities" (September 29, 1995) and "List of Trivial Activities" (January 10, 1996) is discussed in Section 5.2 of this report. Chemical mixtures that had incomplete information were not included in the VOC total. For CY 2001, approximately 3.74 tons were not included in the VOC total after best judgment was used to determine the unlikely presence of VOCs. This approach was discussed with and approved by NMED in March of 1998.

\subsubsection{HAP Emissions}

Section 112(b) of the 1990 Clean Air Act Amendments listed 189 unique HAPs that were identified for potential regulation by EPA. In 1995, caprolactam was delisted as a HAP. Of the remaining 188 listed HAPs, 17 are classes of compounds (e.g., nickel compounds). The use of the 188 listed chemicals in R\&D activities at the Laboratory was evaluated and quantified for the annual emission inventory submittal to NMED.

The ACIS CY 2001 data set was analyzed to identify HAPs used in R\&D activities. The identification process was similar to that used for the VOCs, described in Section 4.9.1. Pure chemicals (i.e., chemicals with CAS numbers), classes of compounds, and mixtures were evaluated to determine if the chemicals themselves were HAPs or if they had HAP constituents. For mixtures, material safety data sheets (MSDS) were reviewed to determine if any HAPs were present and if so, to determine the associated HAP percentages. Listed below are certain chemical types or categories that were classified and removed from this analysis (refer to Section 4.9.1 and Table 5.1 for explanations on the removal of these chemicals).

- Paints,

- Oils,

- Maintenance chemicals,

- Chemicals used to calibrate equipment,

- Container sizes of $1 \mathrm{lb}$ or less,

- Chemicals used in bench-scale chemical analysis,

- Use of office equipment and products,

- Chemicals used for boiler water treatment operations, and

- Chemicals used for oxygen scavenging (deaeration) of water.

Total HAP emissions were estimated by summing (1) pure HAP chemicals, (2) classes of compounds that are HAPs, and (3) the HAP constituents from mixtures. The resulting total amount of HAPs reported for 2001 was 7.4 tons. Based on this analysis, the Laboratory is below the major source threshold of 25 tons for total HAPs and 10 tons for any individual HAP. The top three HAPs used at the Laboratory in 2001 were hydrochloric acid, methanol, and ethylene glycol. In comparison, the total amount of HAPs calculated for 2000 was 6.5 tons. 
The HAP emissions reported generally reflect the quantities procured in the calendar year. In a few cases, however, procurement values and operational processes were further evaluated so that actual air emissions could be reported instead of the procurement quantities. Additional analyses for mercury and hydrochloric acid were performed and are described below.

\section{Mercury}

Large quantities of mercury are used in the shutter systems at the Los Alamos Neutron Science Center (LANSCE) as a barrier for the electron beam. In 2001, the LANSCE shutter system operated as a closed system. No mercury was added to or taken out of the system; therefore, no air emissions of mercury resulted from operations at LANSCE. Mercury is also used in various R\&D activities throughout the Laboratory. All purchases of mercury through the ACIS procurement system were evaluated to determine usage and potential air emissions. In 2001, scientists from Oak Ridge National Laboratory conducted experiments at LANL involving mercury. Approximately 300 pounds of mercury was brought on-site, used in the experiments, and then shipped back to Oak Ridge. Air monitoring during the experiments indicated negligible emissions of mercury. Some purchases of mercury are exempt from the emission inventory requirements because of their use as standards for calibrating laboratory equipment. A total of $6.6 \mathrm{lb}$ of mercury was purchased and used in nonexempt activities.

\section{Hydrochloric Acid}

Waste Facility Management (TA-50-1) purchased multiple 14-gallon carboys of hydrochloric acid $(\mathrm{HCl})$ totaling approximately $1800 \mathrm{lb}$. This $\mathrm{HCl}$ was used for heat exchanger scale cleaning and for the cleaning of electrodialysis reversal membranes. Emissions from these particular activities were estimated to be $0.1 \mathrm{lb}$ based on specific process information and engineering calculations. The remaining procurements were approximately $3470 \mathrm{lb}$, resulting in a reported total for $\mathrm{HCl}$ of 1.75 tons.

\subsection{Permitted Beryllium-Machining Operations}

The Laboratory operates under five 20.2.72 NMAC AQB construction permits** for beryllium-machining operations that are subject to 40 CFR 61, Subpart C, "National Emission Standards for Beryllium." Emissions from these sources were reported at permitted emission levels; however, actual emissions monitored during initial compliance stack tests were below permitted levels. No beryllium machining was performed at TA-3-35 in 2001; therefore, there were no air emissions reported for the facility.

\footnotetext{
** Permit No. 632, issued December 26, 1985. Permit No. 632-M2, issued October 30, 1998. Permit No. 635, issued March 19, 1986. Permit No. 636, issued March 19, 1986. Permit No. 1080-M1-R2, issued March 11, 1998.
} 


\subsection{REPORTING EXEMPTIONS}

Under NMED's AQB Operating Permit Program, specific insignificant or trivial activities are exempt from reporting. NMED has designated exempt sources, activities, or thresholds in the following lists:

- “List of Insignificant Activities," September 29, 1995;

- "List of Trivial Activities," January 10, 1996.

Laboratory sources and activities that qualify as insignificant or trivial as specified in these lists are not included in the 2001 Emissions Inventory Report. The following subsections of this report provide information and examples of the Laboratory's exempt activities, as well as the analyses that were performed to determine the exempt status.

\subsection{Boilers}

The Laboratory's boiler inventory was evaluated against the "List of Insignificant Activities." Specifically, a boiler was considered exempt from the emissions inventory reporting requirements if it met one of the following requirements:

- Any emissions unit...that has the potential to emit no more than one (1) ton per year of any regulated pollutant...; or

- Fuel burning equipment which uses gaseous fuel, has a design rate less than or equal to five (5) million BTU per hour, and is used solely for heating buildings for personal comfort or for producing hot water for personal use.

Any boiler that was not used exclusively for comfort heating or hot water was evaluated for the one (1) ton per year exemption. For purposes of determining the exemption, the boiler design ratings were used to estimate the potential to emit. Any boiler not qualifying for one of these two exemptions was included in the report.

\subsection{VOC Emissions}

A number of insignificant and trivial activities were applicable for exempting materials from the VOC R\&D total in the report. The basis of the exemptions and the corresponding insignificant or trivial activities are explained in Table 5.1.

Fuels such as propane, kerosene, and acetylene were analyzed separately and are not listed in Table 5.1. When fuels are burned in an open flame, almost all of these fuels are consumed and the emissions are minimal. Furthermore, under normal conditions, fuels burned with oxygen are reduced to carbon dioxide and water, which are not regulated air pollutants. 
Table 5.1. Exemptions Applied for R\&D Activities

\begin{tabular}{|c|c|c|}
\hline $\begin{array}{c}\text { Basis of } \\
\text { Exemption }\end{array}$ & Activity Type & Activity \\
\hline $\begin{array}{l}\text { Container sizes of } \\
1 \text { pound or less }\end{array}$ & Trivial & $\begin{array}{l}\text { Paint or nonpaint materials dispensed from prepackaged } \\
\text { aerosol cans of } 16 \text {-oz. capacity or less. }\end{array}$ \\
\hline $\begin{array}{l}\text { Chemicals with } \\
\text { vapor pressures } \\
<10-\mathrm{mm} \mathrm{Hg}\end{array}$ & Insignificant & $\begin{array}{l}\text { Any emissions unit, operation, or activity that handles or } \\
\text { stores a liquid with a vapor pressure of less than } \\
10-\mathrm{mm} \mathrm{Hg} \text { or in quantities of less than } 500 \text { gal. }\end{array}$ \\
\hline $\begin{array}{l}\text { Calibration } \\
\text { chemicals }\end{array}$ & Trivial & $\begin{array}{l}\text { Routine calibration and maintenance of laboratory } \\
\text { equipment or other analytical instruments, including } \\
\text { gases used as part of those processes. }\end{array}$ \\
\hline $\begin{array}{l}\text { Maintenance } \\
\text { chemicals and oils }\end{array}$ & Trivial & $\begin{array}{l}\text { Activities that occur strictly for maintenance of grounds } \\
\text { or buildings, including the following: lawn care; pest } \\
\text { control; grinding; cutting; welding; painting; } \\
\text { woodworking; sweeping; general repairs; janitorial } \\
\text { activities; plumbing; re-tarring roofs; installing } \\
\text { insulation; steam-cleaning and water-washing activities; } \\
\text { and paving of roads, parking lots, and other areas. } \\
\text { Activities for maintenance and repair of equipment, } \\
\text { pollution-control equipment, or motor vehicles either } \\
\text { inside or outside of a building. }\end{array}$ \\
\hline $\begin{array}{l}\text { Use of office } \\
\text { equipment and } \\
\text { products }\end{array}$ & Trivial & $\begin{array}{l}\text { Use of office equipment and products, not including } \\
\text { printers or businesses primarily involved in photographic } \\
\text { reproduction. }\end{array}$ \\
\hline $\begin{array}{l}\text { Chemicals used for } \\
\text { boiler water } \\
\text { treatment }\end{array}$ & Trivial & $\begin{array}{l}\text { Boiler water treatment operations, not including cooling } \\
\text { towers. }\end{array}$ \\
\hline $\begin{array}{l}\text { Chemicals used for } \\
\text { oxygen scavenging }\end{array}$ & Trivial & Oxygen scavenging (deaeration of water). \\
\hline $\begin{array}{l}\text { Chemicals used in } \\
\text { bench-scale } \\
\text { chemical analysis }\end{array}$ & Trivial & $\begin{array}{l}\text { Bench-scale laboratory equipment used for physical or } \\
\text { chemical analysis but not lab fume hoods or vents. } \\
\text { Note: This exemption was applied only to biological } \\
\text { research solutions. Otherwise, this exemption was not } \\
\text { applied. }\end{array}$ \\
\hline
\end{tabular}




\subsection{HAP Emissions}

A HAP R\&D activity exemption analysis, similar to the VOC R\&D activity exemption analysis, resulted in application of several of the same exemptions from NMED's AQB "List of Trivial Activities" and "List of Insignificant Activities" (refer to Table 5.1).

\subsection{Paints}

An exemption analysis was performed for VOC and HAP emissions resulting from painting activities conducted at the Laboratory. Paint information for 2001 was gathered from the work control databases and the Laboratory's procurement and inventory systems. These records were evaluated for applicability of exemptions for trivial and insignificant activities.

The following exemptions from NMED's AQB Operating Permit Program "List of Trivial Activities" were used in the paint analysis:

- Activities that occur strictly for maintenance of grounds or buildings, including the following: lawn care; pest control; grinding; cutting; welding; painting; woodworking; sweeping; general repairs; janitorial activities; plumbing; re-tarring roofs; installing insulation; steam-cleaning and water-washing activities; and paving of roads, parking lots, and other areas.

- Activities for maintenance and repair of equipment, pollution control equipment, or motor vehicles either inside or outside of a building.

- Paint or nonpaint materials dispensed from prepackaged aerosol cans of 16-ounce or less capacity.

The corresponding amounts of paint were totaled for painting activities that did not qualify for one of the exemptions listed above. This paint total for CY 2001 was determined to be $3135 \mathrm{lb}$ (1.57 tons), which further qualified for the following insignificant activity:

Surface coating of equipment, including spray painting and roll coating, for sources with facility-wide total cleanup solvent and coating actual emissions of less than two (2) tons per year.

All emissions from paints and painting activities were exempt as insignificant or trivial activities and therefore were not included in the 2001 Emissions Inventory Report.

\subsection{Generators}

The Laboratory has an inventory of approximately 125 portable generators. Portable generators are used at the Laboratory for temporary operations requiring remote power or to provide emergency backup power during power outages at various sites. The portable generators are fueled by gasoline and/or diesel fuel.

In addition to the portable generators, the Laboratory maintains and operates approximately 45 stationary generators. Stationary generators are used on standby (emergency) status to provide power to critical systems at the Laboratory during power outages. The stationary generators are fueled by natural gas, gasoline, or diesel. 
The insignificant activity exemptions applicable to the Laboratory's generators are the following:

- Portable engines and portable turbines that have a design capacity...less than or equal to - $\quad$ 200-HP engine if fueled by diesel or natural gas, and

- $\quad$ 500-HP engine if fueled by gasoline....

- Emergency generators that comply with the definition of standby equipment....

Standby equipment is defined in NMED's AQB “List of Insignificant Activities” as “an emissions unit which on a temporary basis replaces equipment used in normal operation, and which either has an allowable emission rate or potential to emit for each fee pollutant that is equal to or less than the equipment replaced, or which does not operate for a period exceeding 500 hours per calendar year."

On the basis of their size, the portable generators used for temporary power at remote locations are exempt from emissions-inventory reporting requirements. Since all of the stationary generators are designated as standby equipment under the Operating Permit Program and are used solely to provide emergency backup power for less than 500 hours per year, they are insignificant sources and, therefore, are exempt from emissionsinventory reporting requirements.

\subsection{EMISSIONS SUMMARY}

Table 6.1 presents facility-wide actual emissions of criteria pollutants for 2001, as reported in the emission inventory. Table 6.2 presents facility-wide actual emissions for HAPs. Graphical representations of emissions are also provided. Figures 6.1 and 6.2 show emissions by source and by year respectively. Figure 6.3 represents VOC and HAP emissions from R\&D activities.

The Laboratory's reported emissions for 2001 are tabulated and summarized in Attachment A. Emission unit information and emissions estimates are included in Attachment B. The 2001 Emissions Inventory Report as submitted to NMED is presented in Attachment C. As mentioned, it is formatted to be compatible with AIRS.

Table 6.1. LANL Facility-Wide Criteria Pollutant Emissions for 2001

\begin{tabular}{|c|c|}
\hline Pollutant & Actual Emissions (tons/yr) \\
\hline NOx & 93.8 \\
\hline SOx & 0.8 \\
\hline CO & 29.1 \\
\hline PM & 5.5 \\
\hline VOC & 24.1 \\
\hline
\end{tabular}


Table 6.2. LANL HAPs Emissions from Facility-Wide Chemical Use for 2001

\begin{tabular}{|c|c|}
\hline Pollutant & Actual Emissions (tons/yr) \\
\hline Total HAPs & 7.4 \\
\hline Top 5 HAPs & \\
\hline Hydrochloric Acid & 1.74 \\
\hline Methanol & 0.91 \\
\hline Ethylene Glycol & 0.72 \\
\hline Acetonitrile & 0.66 \\
\hline Trichloroethylene & 0.51 \\
\hline
\end{tabular}

Attachment $\mathrm{C}$ is a copy of the data in spreadsheet form that was submitted to NMED for reportable emission sources. Several notable changes occurred to the emission inventory sources for 2001. First, Stack ID No. 002, which has been used for the three main power plant boilers at TA-3, has been deleted and replaced with three separate Stack ID Nos. $(032,033,034)$.

Second, two aging boilers at TA-55 were replaced with new low-NOx boilers in 2001. Therefore, two new Stack ID Nos. were added to the inventory (037 and 038). Emissions are shown for both the old and the new boilers because this replacement project occurred in the middle of the year.

Finally, LANL installed and operated three new air curtain destructors to burn wood and brush from tree thinning activities. The tree thinning activities are being conducted as part of the Laboratory's wildfire mitigation plan. Emissions from both the wood burned and the diesel fuel used is included. Three new Stack IDs for these sources (not yet assigned numbers) are included in this inventory. Several existing sources (beryllium machining at TA-3-141, degreasers at TA-46-24, and the rock crusher) did not operate in 2001.

Figure 6.1 shows the air-pollutant emissions by source, excluding beryllium, aluminum, and HAPs. As the figure shows, the TA-3 steam plant is the primary source of $\mathrm{NO}_{\mathrm{x}}, \mathrm{SO}_{\mathrm{x}}$, $\mathrm{PM}$, and $\mathrm{CO}$ emissions. This graph also shows that $\mathrm{R} \& \mathrm{D}$ activities are the primary source of VOC emissions.

The Laboratory has initiated a project to install flue gas recirculation (FGR) equipment on the TA-3 steam plant boilers to reduce the $\mathrm{NO}_{\mathrm{x}}$ emissions by approximately $70 \%$. This project was initiated in 1999 and was anticipated to be completed by end of fiscal year (FY) 2001. As of April 1, 2001, the installation of FGR equipment had not been completed. When this equipment is fully implemented, emissions from the Laboratory's TA-3 steam plant will be significantly reduced. 


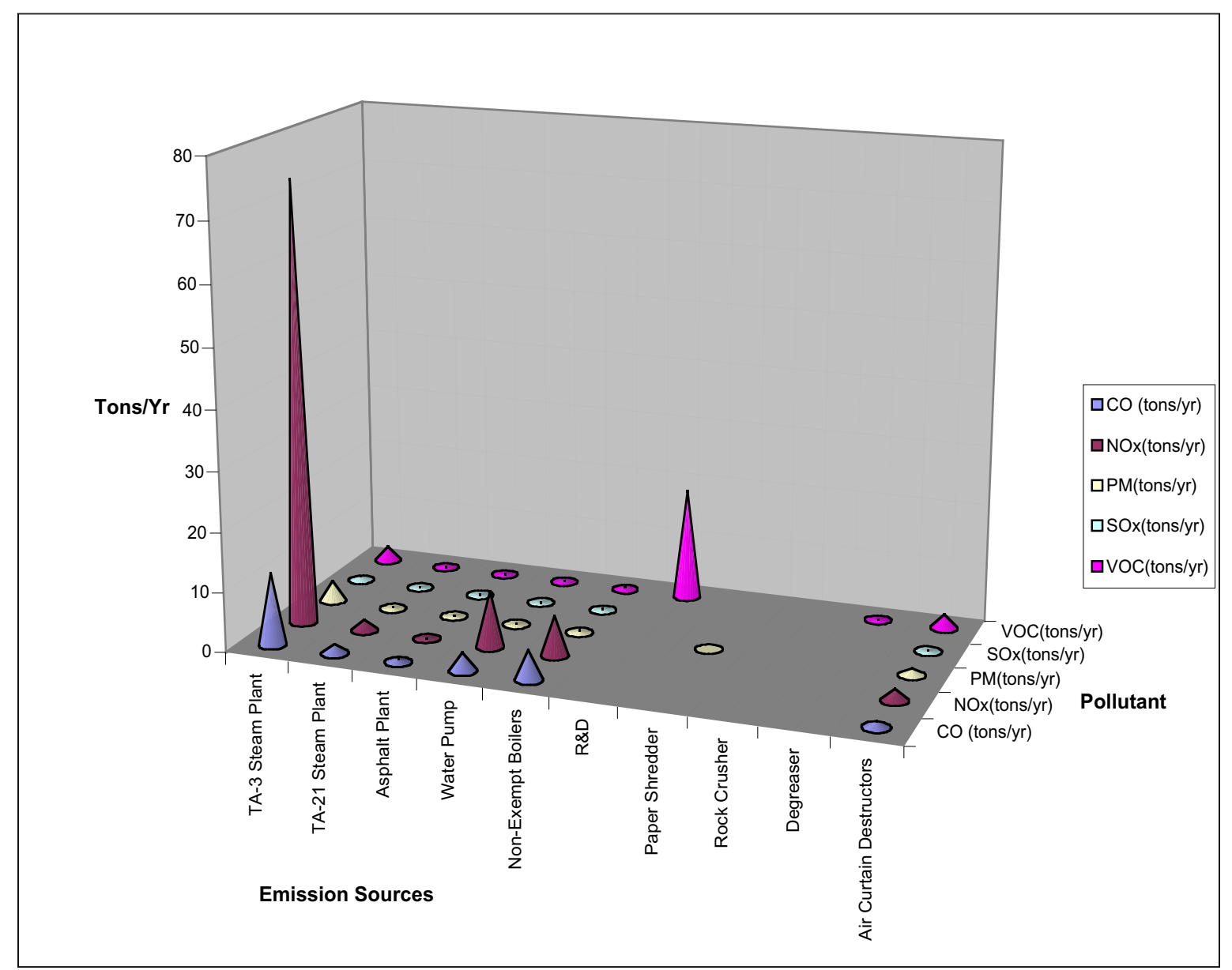

Figure 6.1. Emissions of Criteria Pollutants by Source in 2001.

Figure 6.2 compares the past five years' emissions for criteria air pollutants and VOCs reported to NMED. There are some differences in the emissions from 2000 to 2001. The Laboratory operated at reduced levels for several months in 2000 because of the focus on recovery efforts associated with the Cerro Grande fire. The 2001 emissions are similar to emission levels reported in 1999.

Figure 6.3 represents VOC and HAP emissions from R\&D activities. As shown, the VOC and HAP emissions from R\&D activities are greater in 2001 than in 2000. The decrease in VOC and HAP emissions from 2000 was largely related to an overall decrease in chemical purchases in 2000 and the reduced level of operations during and immediately after the Cerro Grande fire. Chemical purchases resumed normally during 2001. 


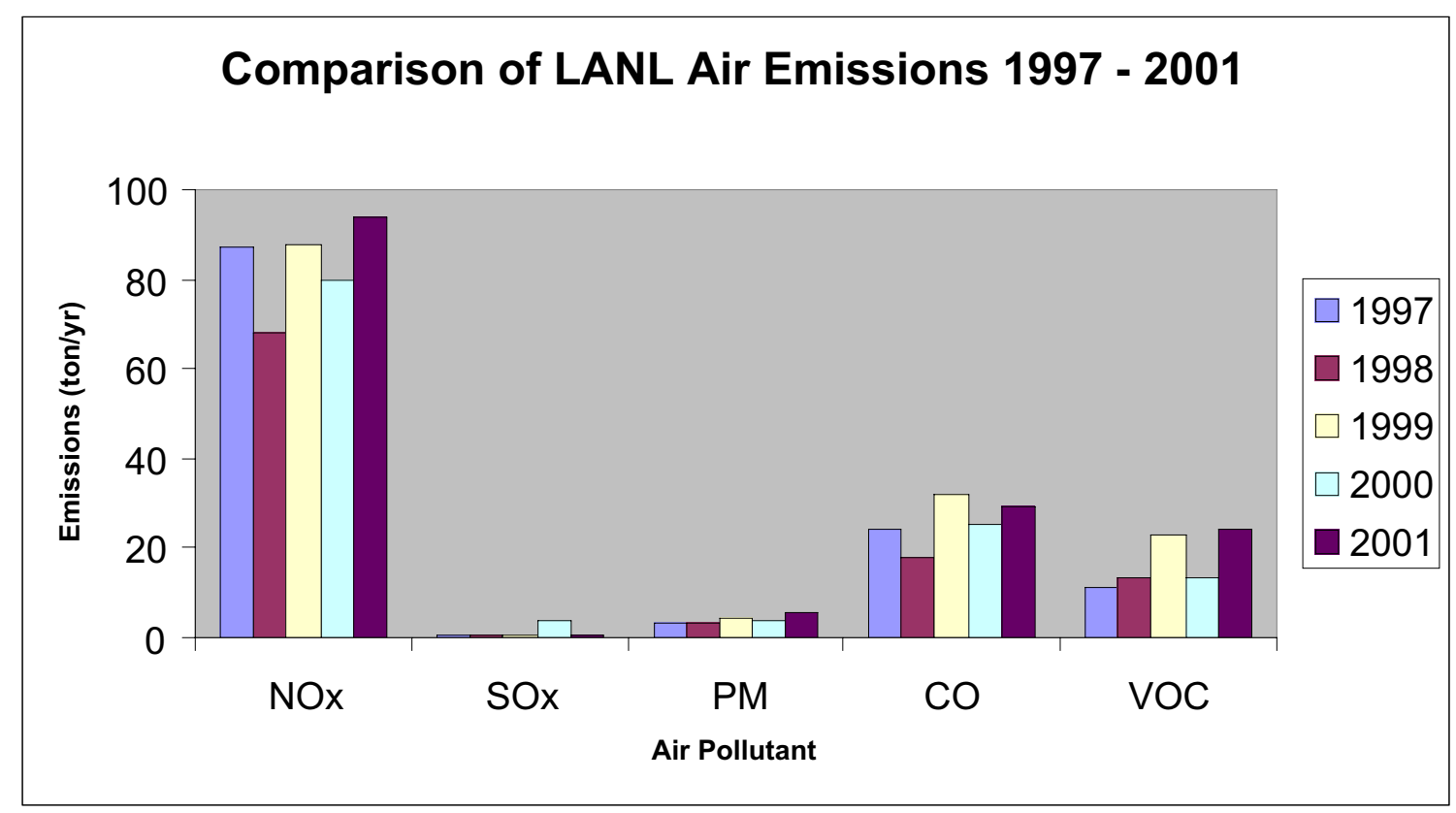

Figure 6.2. Emissions Generated in 1997, 1998, 1999, 2000, and 2001.

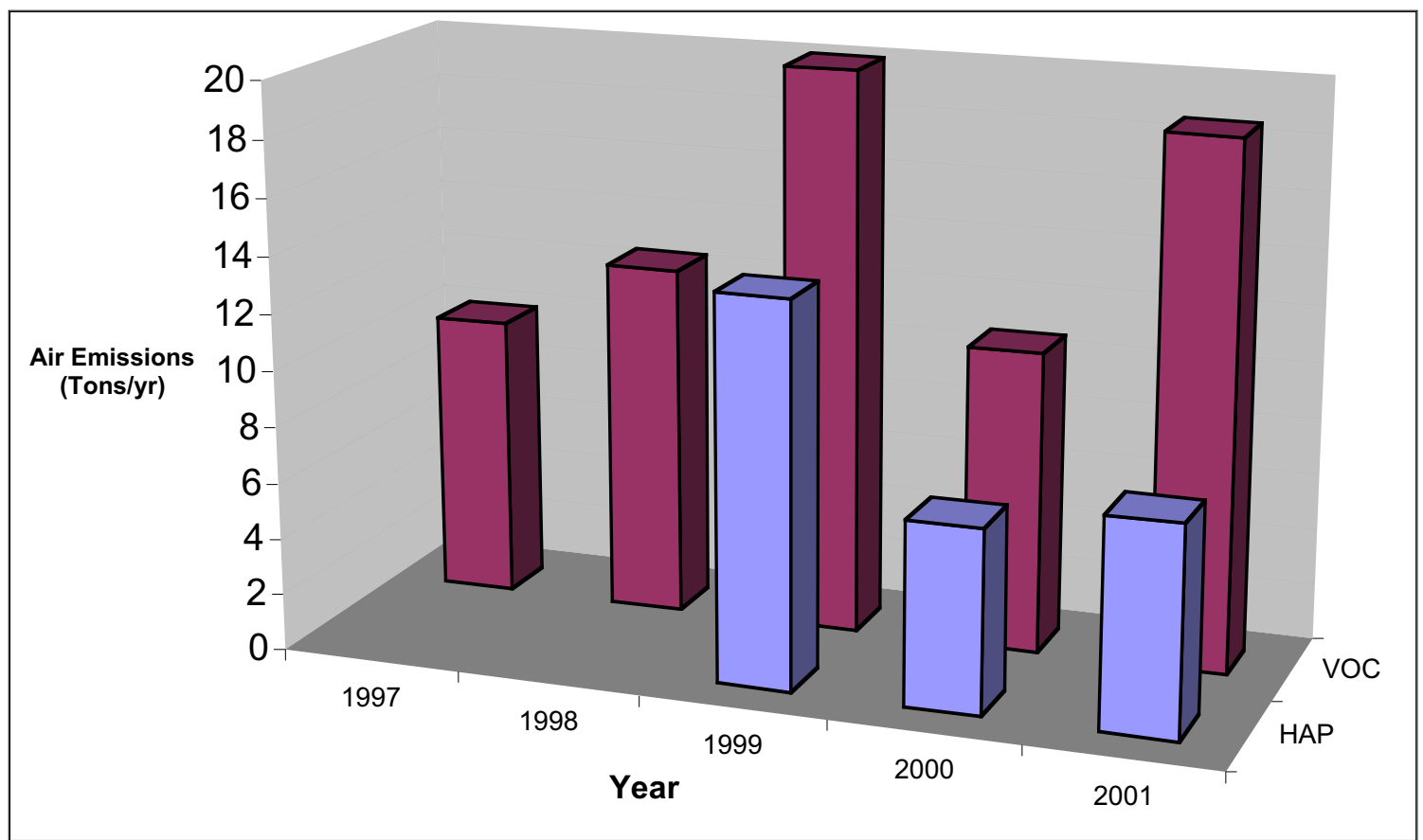

Figure 6.3. VOC and HAP Emissions from R\&D Activities. 
Attachment A. Emissions Inventory Summary

\begin{tabular}{|c|c|c|c|c|c|c|c|c|}
\hline \multirow[b]{2}{*}{ Stack Number } & \multirow[b]{2}{*}{ Source Description } & \multicolumn{7}{|c|}{2001 Estimated Actual Emissions } \\
\hline & & $\begin{array}{r}\text { Al } \\
(\mathrm{lb} / \mathrm{yr})\end{array}$ & $\begin{array}{r}\mathrm{Be} \\
(\mathrm{lb} / \mathrm{yr})\end{array}$ & $\begin{array}{r}\text { NOx } \\
\text { (ton/yr) }\end{array}$ & $\begin{array}{r}\text { SOx } \\
\text { (ton/yr) }\end{array}$ & $\begin{array}{r}\mathrm{PM} \\
\text { (ton/yr) }\end{array}$ & $\begin{array}{r}\mathrm{CO} \\
\text { (ton/yr) }\end{array}$ & $\begin{array}{r}\mathrm{VOC} \\
\text { (ton/yr) }\end{array}$ \\
\hline 001 & BE Shop, TA-3, BIdg 39, Room $16^{(a)}$ & 0.00 & 0.000 & 0.00 & 0.00 & 0.000 & 0.00 & 0.00 \\
\hline 002 & Edgemoor BLRS 3EA TA-3-22 & 0.00 & 0.00 & 0.0 & 0.0 & 0.0 & 0.0 & 0.0 \\
\hline 003 & Steam Plant TA-16-Bldg 540 & 0.00 & 0.00 & 0.00 & 0.00 & 0.00 & 0.00 & 0.00 \\
\hline 004 & Industrial BLRS 3 TA-21-357 & 0.00 & 0.00 & 1.85 & 0.01 & 0.14 & 1.55 & 0.10 \\
\hline 005 & TD Site Not Operating Stack & 0.00 & 0.00 & 0.00 & 0.00 & 0.00 & 0.00 & 0.00 \\
\hline 006 & BE Machining TA-35, Bldg $213^{(\mathrm{D})}$ & 0.00 & 0.0008 & 0.00 & 0.00 & 0.0000 & 0.00 & 0.00 \\
\hline 007 & BE Machining TA-3, Bldg $141^{(\mathrm{D})}$ & 0.00 & 0.0077 & 0.00 & 0.00 & 0.0000 & 0.00 & 0.00 \\
\hline 008 & BE Machining TA-3, Bldg $102^{\text {(a) }}$ & 0.00 & 0.000 & 0.00 & 0.00 & 0.000 & 0.00 & 0.00 \\
\hline 009 & BE Shop, TA-3-35 - Not Built & 0.00 & 0.00 & 0.00 & 0.00 & 0.00 & 0.00 & 0.00 \\
\hline 010 & BE Cutting and Bead Dressing ${ }^{(\mathrm{D})}$ & 0.004 & 0.004 & 0.00 & 0.00 & 0.0000 & 0.00 & 0.00 \\
\hline 011 & TA-55-4 BE Metallography ${ }^{(\mathrm{D})}$ & 0.00 & 0.0066 & 0.00 & 0.00 & 0.0000 & 0.00 & 0.00 \\
\hline 012 & Solid Waste Fired Boiler - Not Built & 0.00 & 0.00 & 0.00 & 0.00 & 0.00 & 0.00 & 0.00 \\
\hline 013 & Asphalt Rotary Dryer TA-3-73 & 0.00 & 0.00 & 0.03 & 0.006 & 0.09 & 0.52 & 0.01 \\
\hline 014 & Water Pump Engine & 0.00 & 0.00 & 9.41 & 0.004 & 0.06 & 3.01 & 0.19 \\
\hline 015 & Boiler (TA-48-1) BS-1 & 0.00 & 0.00 & 0.45 & 0.003 & 0.03 & 0.38 & 0.02 \\
\hline 016 & Boiler (TA-48-1) BS-2 & 0.00 & 0.00 & 0.45 & 0.003 & 0.03 & 0.38 & 0.02 \\
\hline 017 & Boiler (TA-48-1) BS-6 & 0.00 & 0.00 & 0.60 & 0.004 & 0.05 & 0.50 & 0.03 \\
\hline 018 & Boiler (TA-53-365) BHW-1 & 0.00 & 0.00 & 0.60 & 0.004 & 0.05 & 0.50 & 0.03 \\
\hline 019 & Boiler (TA-53-365) BHW-2 & 0.00 & 0.00 & 0.60 & 0.004 & 0.05 & 0.50 & 0.03 \\
\hline 020 & Boiler (TA-59-1) BHW-1 & 0.00 & 0.00 & 0.45 & 0.003 & 0.03 & 0.38 & 0.02 \\
\hline 021 & Boiler (TA-59-1) BHW-2 & 0.00 & 0.00 & 0.45 & 0.003 & 0.03 & 0.38 & 0.02 \\
\hline 022 & Boiler (TA-55-6) BHW-1-Removed & 0.00 & 0.00 & 0.00 & 0.000 & 0.00 & 0.00 & 0.00 \\
\hline 023 & Boiler (TA-55-6) BHW-2 & 0.00 & 0.00 & 0.90 & 0.002 & 0.03 & 1.10 & 0.02 \\
\hline 024 & Boiler \& Backup (TA-16, Plant 5) & 0.00 & 0.00 & 0.26 & 0.004 & 0.05 & 0.26 & 0.04 \\
\hline 025 & Boiler \& Backup (TA-16, Plant 6) & 0.00 & 0.00 & 0.00 & 0.000 & 0.00 & 0.00 & 0.00 \\
\hline 026 & Rock Crusher ${ }^{(a)}$ & NA & NA & 0.00 & 0.000 & 0.00 & 0.00 & 0.00 \\
\hline 027 & Paper Shredder & NA & NA & NA & NA & 0.0007 & NA & NA \\
\hline 028 & Degreaser TA-55-4 & NA & NA & NA & NA & NA & NA & 0.01 \\
\hline 029 & Degreaser TA-46-24 Cold Ultrasonic ${ }^{(a)}$ & NA & NA & NA & NA & NA & NA & 0.00 \\
\hline 030 & Degreaser TA-46-24 Inhouse ${ }^{(a)}$ & NA & NA & NA & NA & NA & NA & 0.00 \\
\hline 031 & R\&D VOC & NA & NA & NA & NA & NA & NA & 18.60 \\
\hline 032 & TA-3-223 Boiler 1 (Edgemoor Iron Works) & 0.00 & 0.00 & 19.64 & 0.516 & 0.97 & 4.77 & 0.63 \\
\hline 033 & TA-3-223 Boiler 2 (Edgemoor Iron Works) & 0.00 & 0.00 & 30.16 & 0.112 & 1.41 & 7.40 & 1.02 \\
\hline 034 & TA-3-223 Boiler 3 (Edgemoor Iron Works) & 0.00 & 0.00 & 24.09 & 0.089 & 1.12 & 5.91 & 0.81 \\
\hline 035 & Tank TA-3-26 (Fuel Oil) & NA & NA & NA & NA & NA & NA & 0.01 \\
\hline 036 & Tank TA-3-779 (Fuel Oil) & NA & NA & NA & NA & NA & NA & 0.03 \\
\hline 037 & TA-55-6 Sellers Boiler-BHW-1B & 0.00 & 0.00 & 1.44 & 0.01 & 0.15 & 0.40 & 0.06 \\
\hline 038 & TA-55-6 Sellers Boiler-BHW-2B & 0.00 & 0.00 & 0.54 & 0.002 & 0.06 & 0.15 & 0.02 \\
\hline New & Air Curtain Destructor S-127 & NA & NA & 0.19 & 0.005 & 0.02 & 0.10 & 0.25 \\
\hline New & Air Curtain Destructor-Trench Burner \#1 & NA & NA & 0.97 & 0.03 & 0.62 & 0.50 & 1.16 \\
\hline New & Air Curtain Destructor-Trench Burner \#2 & NA & NA & 0.72 & 0.02 & 0.51 & 0.39 & 0.95 \\
\hline \multirow{2}{*}{\multicolumn{2}{|c|}{$\begin{array}{r}\text { Total Emissions (lb/yr): } \\
\text { Total Emissions (tons/yr): }\end{array}$}} & 0.004 & 0.019 & & & & & \\
\hline & & 2.05E-06 & $9.60 \mathrm{E}-06$ & 93.80 & 0.82 & 5.50 & 29.08 & 24.12 \\
\hline
\end{tabular}

(a) Source did not operate in 2001

(b) Emissions based on permit allowables

(c) Stack No. 2 should be deleted from Emission Inventory (originally 1 stack ID assigned for 3 large boilers). It is replaced with separate stack numbers for each boiler (see Stack No. 032, 033 and 034). 


\section{Attachment B. Emission Calculation Worksheets for Individual Emission Units}

\begin{tabular}{|c|c|c|c|c|c|c|c|}
\hline \multirow[t]{10}{*}{ Stack No. 004} & \multicolumn{7}{|c|}{ TA-21-357 Steam Plant (Industrial Boilers, 12 MMBTU/hr) } \\
\hline & \multicolumn{7}{|c|}{ Natural Gas Emission Factors (Ib/MMSCF) } \\
\hline & Gas (MMCF) ${ }^{b}$ & $\mathrm{NO}_{\mathrm{x}}$ & $\mathrm{SO}_{\mathrm{x}}$ & \begin{tabular}{l|l}
$\mathrm{PM}$ & \\
\end{tabular} & $\mathrm{PM}-10^{\circ}$ & $\mathrm{CO}$ & VOC \\
\hline & 37 & 100 & 0.6 & 7.6 & 7.6 & 84 & 5.5 \\
\hline & Emissions (ton) & 1.85 & 0.01 & 0.14 & 0.14 & 1.55 & 0.10 \\
\hline & & \multicolumn{6}{|c|}{ Fuel Oil Emission Factors (lb/1000 gal) ${ }^{d}$} \\
\hline & Oil (1000 gal) ${ }^{\mathrm{b}}$ & $\mathrm{NO}_{\mathrm{x}}$ & $\mathrm{SO}_{\mathrm{x}}^{\mathrm{e}}$ & \begin{tabular}{l|l}
$\mathrm{PM}$ & \\
\end{tabular} & \begin{tabular}{l|l}
$\mathrm{PM}-10^{\mathrm{n}}$ \\
\end{tabular} & $\mathrm{CO}$ & VOC $^{f}$ \\
\hline & 0 & 20 & 49.0 & 2 & 1 & 5 & 0.2 \\
\hline & Emissions (ton) & 0.0 & 0.0 & 0.0 & 0.0 & 0.0 & 0.0 \\
\hline & TOTAL (ton/yr) & 1.85 & 0.01 & 0.14 & 0.14 & 1.55 & 0.10 \\
\hline Stack No. 013 & \multicolumn{7}{|c|}{ TA-3-73 Asphalt Plant } \\
\hline & & \multicolumn{6}{|c|}{ Emission Factors (lb/ton) ${ }^{g}$} \\
\hline & $\begin{array}{c}\text { Asphalt } \\
\text { Production (tons) } \\
\end{array}$ & $\mathrm{NO}_{x}$ & $\mathrm{SO}_{\mathrm{x}}$ & $\mathrm{PM}^{\mathrm{h}}$ & $\mathrm{PM}-10^{\circ}$ & $\mathrm{CO}$ & VOC \\
\hline & 2,576 & 0.025 & 0.0046 & 0.07 & 0.07 & 0.4 & 0.0082 \\
\hline & Emissions (ton) & 0.032 & 0.006 & $\begin{array}{r}0.090 \\
\end{array}$ & 0.090 & 0.515 & 0.011 \\
\hline Stack No. 014 & \multicolumn{7}{|c|}{ TA-54 Water Pump (700 Horsepower) } \\
\hline & & \multicolumn{6}{|c|}{ Emission Factors } \\
\hline $\begin{array}{l}\text { Hours of } \\
\text { Operation }\end{array}$ & Gas $(\mathrm{MMCF})^{\mathrm{b}}$ & $\mathrm{NO}_{\mathrm{x}}(\mathrm{g} / \mathrm{hp}-\mathrm{hr})^{\mathrm{i}}$ & $\begin{array}{c}\mathrm{SO}_{\mathrm{x}} \\
(\mathrm{Ib} / \mathrm{MMBTU})^{\mathrm{k}}\end{array}$ & \begin{tabular}{c|} 
PM \\
${\text { (lb/MMBTU })^{\mathrm{k}}}$
\end{tabular} & $\begin{array}{c}\text { PIM-10 } \\
(\mathrm{Ib} / \mathrm{MMBTU})^{\circ}\end{array}$ & $\mathrm{CO}(\mathrm{g} / \mathrm{hp}-\mathrm{hr})^{\mathrm{i}}$ & $\begin{array}{c}\text { VOC } \\
(\mathrm{g} / \mathrm{hp}-\mathrm{hr})^{\prime}\end{array}$ \\
\hline 2440 & 12.2 & 5 & $5.88 \mathrm{E}-04$ & $9.91 \mathrm{E}-03$ & $9.91 \mathrm{E}-03$ & 1.6 & 0.1 \\
\hline & Emissions (ton) & 9.41 & 0.0037 & 0.06 & 0.06 & 3.01 & 0.19 \\
\hline Stack No. 032 & \\
\hline & \multicolumn{7}{|c|}{$\begin{array}{r}\text { TA-3-22 Steam Plant-Boiler \# } 1 \text { (Edgemoor Boiler, 210 MMBTU/hr) } \\
\text { Natural Gas Emission Factors (lb/MMSCF) }\end{array}$} \\
\hline & Gas (MMCF) ${ }^{b}$ & $\mathrm{NO}_{\mathrm{x}}{ }^{\mathrm{c}}$ & $\mathrm{SO}_{\mathrm{x}}$ & \begin{tabular}{l|l}
$\mathrm{PM}$ & \\
\end{tabular} & $\mathrm{PM}-10^{\circ}$ & $\mathrm{CO}^{\prime}$ & VOC \\
\hline & 223.1 & 163 & 0.6 & 7.6 & 7.6 & 40 & 5.5 \\
\hline & Emissions (ton) & 18.2 & 0.1 & $\begin{array}{r}0.8 \\
\end{array}$ & 0.8 & 4.5 & 0.6 \\
\hline & & \multicolumn{6}{|c|}{ Fuel Oil Emission Factors (lb/1000 gal $)^{\mathrm{d}}$} \\
\hline & Oil (1000 gal) ${ }^{b}$ & $\mathrm{NO}_{\mathrm{x}}$ & $\mathrm{SO}_{\mathrm{x}}^{\mathrm{m}}$ & \begin{tabular}{l|l}
$\mathrm{PM}$ & \\
\end{tabular} & $\mathrm{PM}-10^{\mathrm{n}}$ & $\mathrm{CO}$ & VOC $^{f}$ \\
\hline & 121.5 & 24 & 7.39 & 2 & 1 & 5 & 0.2 \\
\hline & Emissions (ton) & 1.46 & 0.45 & 0.12 & 0.06 & 0.30 & 0.01 \\
\hline & TOTAL (ton/yr) & 19.6 & 0.5 & \begin{tabular}{r|r}
1.0 \\
\end{tabular} & 0.9 & 4.8 & 0.6 \\
\hline Stack No. 033 & \multicolumn{7}{|c|}{ TA-3-22 Steam Plant - Boiler \# 2 (Edgemoor Boiler, 210 MMBTU/hr) } \\
\hline & & \multicolumn{6}{|c|}{ Natural Gas Emission Factors (Ib/MMSCF) ${ }^{\mathrm{a}}$} \\
\hline & Gas (MMCF) & $\mathrm{NO}_{\mathrm{x}}{ }^{\mathrm{c}}$ & $\mathrm{SO}_{\mathrm{x}}$ & \begin{tabular}{l|l}
$\mathrm{PM}$ & \\
\end{tabular} & $\mathrm{PM}-10^{\circ}$ & $\mathrm{CO}^{1}$ & VOC \\
\hline & 370.0 & 163 & 0.6 & 7.6 & 7.6 & 40 & 5.5 \\
\hline & Emissions (ton) & 30.2 & 0.1 & 1.4 & 1.4 & 7.4 & 1.0 \\
\hline & & \multicolumn{6}{|c|}{ Fuel Oil Emission Factors (lb/1000 gall $)^{\mathrm{d}}$} \\
\hline & Oil $\left(1000\right.$ gal) ${ }^{b}$ & $\mathrm{NO}_{\mathrm{x}}$ & $\mathrm{SO}_{\mathrm{x}}^{\mathrm{m}}$ & \begin{tabular}{l|l} 
PM & \\
\end{tabular} & PM-10 & $\mathrm{CO}$ & $\operatorname{VOC}^{f}$ \\
\hline & 0.4 & 24 & 7.39 & 2 & 1 & 5 & 0.2 \\
\hline & Emissions (ton) & 0.00 & 0.00 & 0.00 & 0.00 & 0.00 & 0.00 \\
\hline & TOTAL (ton/yr) & 30.2 & 0.1 & 1.4| & 1.4 & 7.4 & 1.0 \\
\hline
\end{tabular}




\begin{tabular}{|c|c|c|c|c|c|c|c|}
\hline \multirow[t]{2}{*}{ Stack No. 034} & \multicolumn{7}{|c|}{ TA-3-22 Steam Plant - Boiler \# 3 (Edgemoor Boiler, 210 MMBTU/hr) } \\
\hline & \multicolumn{7}{|c|}{ Natural Gas Emission Factors (lb/MMSCF) } \\
\hline & Gas (MMCF) ${ }^{\mathrm{b}}$ & $\mathrm{NO}_{\mathrm{x}}{ }^{\mathrm{c}}$ & $\mathrm{SO}_{\mathrm{x}}$ & \begin{tabular}{l|l}
$P M$ &
\end{tabular} & \begin{tabular}{l|l} 
PM-10 & \\
\end{tabular} & $\mathrm{CO}^{\prime}$ & VOC \\
\hline & 295.6 & 163 & 0.6 & 7.6 & 7.6 & 40 & 5.5 \\
\hline & Emissions (ton) & 24.1 & 0.1 & 1.1 & 1.1 & 5.9 & 0.8 \\
\hline & & & Fuel C & nission $\mathrm{Fa}$ & $\mathrm{rs}(\mathrm{lb} / 1000 \mathrm{~g}$ & & \\
\hline & Oil (1000 gal) ${ }^{b}$ & $\mathrm{NO}_{\mathrm{x}}$ & $\mathrm{SO}_{\mathrm{x}}^{\mathrm{m}}$ & \begin{tabular}{l|}
$\mathrm{PM}$ \\
\end{tabular} & PM-10 & $\mathrm{CO}$ & $\operatorname{VOC}^{f}$ \\
\hline & 0.06 & 24 & 7.39 & 2 & 1 & 5 & 0.2 \\
\hline & Emissions (ton) & 0.00 & 0.00 & 0.00 & 0.00 & 0.00 & 0.00 \\
\hline & TOTAL (ton/yr) & 24.1 & 0.1 & 1.1 & 1.1 & 5.9 & 0.8 \\
\hline & TOTAL & 85.2 & 0.7 & 3.8 & 3.7 & 23.2 & 2.8 \\
\hline
\end{tabular}

a AP-42, 7/98, Section. 1.4, Natural Gas Combustion , Tables 1.4-1, 1.4-2

${ }^{\mathrm{b}}$ Fuel usage obtained from Jerry Gonzales, FWO-UI

c Source Test on Unit 3, 8/29/95 (Title V Application, December 1995)

${ }^{d}$ AP-42, 9/98, Section. 1.3, Fuel Oil Combustion, Table 1.3-1 with Errata

e $\mathrm{S}=$ weight $\%$ sulfur in oil (Title V Application, December 1995) Boilers <100 MMBtu/hr: $\mathrm{SO}_{\mathrm{x}}$ Emission Factor $=144$ * $\mathrm{S}$

$$
\mathrm{S}(\%)=\quad 0.34
$$

${ }^{f}$ AP-42, 9/98, Section 1.3, Fuel Oil Combustion , Table 1.3-3 NMTOC

${ }^{9}$ AP-42, 12/2000, Section 11.1, Hot Mix Asphalt Plants , Table 11.1-5 and 11.1-6

${ }^{\mathrm{h}}$ Source Test, 8/25/93 (Title V Application, December 1995)

'Emission Factors from Manufacturer

Sample Calculation: (hr of op)(hp)(EF g/hp-hr)/453.593 g/lb

Conversion: $\quad 453.593 \mathrm{~g} / \mathrm{lb}$

$$
\text { jFuel Rate: } \quad 5000 \mathrm{scf}=1 \text { hour }
$$

${ }^{k}$ AP-42, 8/2000, Section 3.2, Heavy Duty Nat. Gas-fired Pipeline Compressor Engines and Turbines , Table 3.2-3

'AP-42, 1/95, Section. 1.4, Natural Gas Combustion , Table 1.4-2. Consistent with previous stack tests.

${ }^{\mathrm{m}}$ Boilers $>100 \mathrm{MMBtu} / \mathrm{hr}: \mathrm{SO}_{\mathrm{x}}$ Emission Factor $=147.7{ }^{*} \mathrm{~S}$

Sulfur content per Analysis on oil in tanks in August 2001

$$
\mathrm{S}(\%)=\quad 0.05
$$

${ }^{\mathrm{n}}$ AP-42 9/98, Section 1.3, Fuel Oil Combustion, Table 1.3-6

${ }^{\circ}$ Emission factors for natural gas of PM-10 are roughly equal to those of PM, Natural Gas Combustion, Table 1.4-2

* Assume all SOx is converted to sulfuric acid

${ }^{1}$ AP-42, Table 1.4-2, July 1998

${ }^{2}$ AP-42, Table 1.3-11, September 1998

${ }^{3}$ AP-42, Table 11.1-11, December 2000

${ }^{4}$ AP-42, Table 1.4-4, July 1998

${ }^{5}$ AP-42, Table 1.3-11, September 1998

${ }^{6}$ AP-42, Table 11.1-11, December 2000

${ }^{7}$ AP-42, Table 1.4-3, July 1998

${ }^{8}$ AP-42, Table 1.3-9, September 1998

${ }^{9}$ AP-42, Table 11.1-9, December 2000

${ }^{10}$ EPCRA PAC Guidance Document, Table 2-3 
2001 Emissions Inventory Report_-Small Boilers with Stack Parameters and Estimated 2001 Emissions

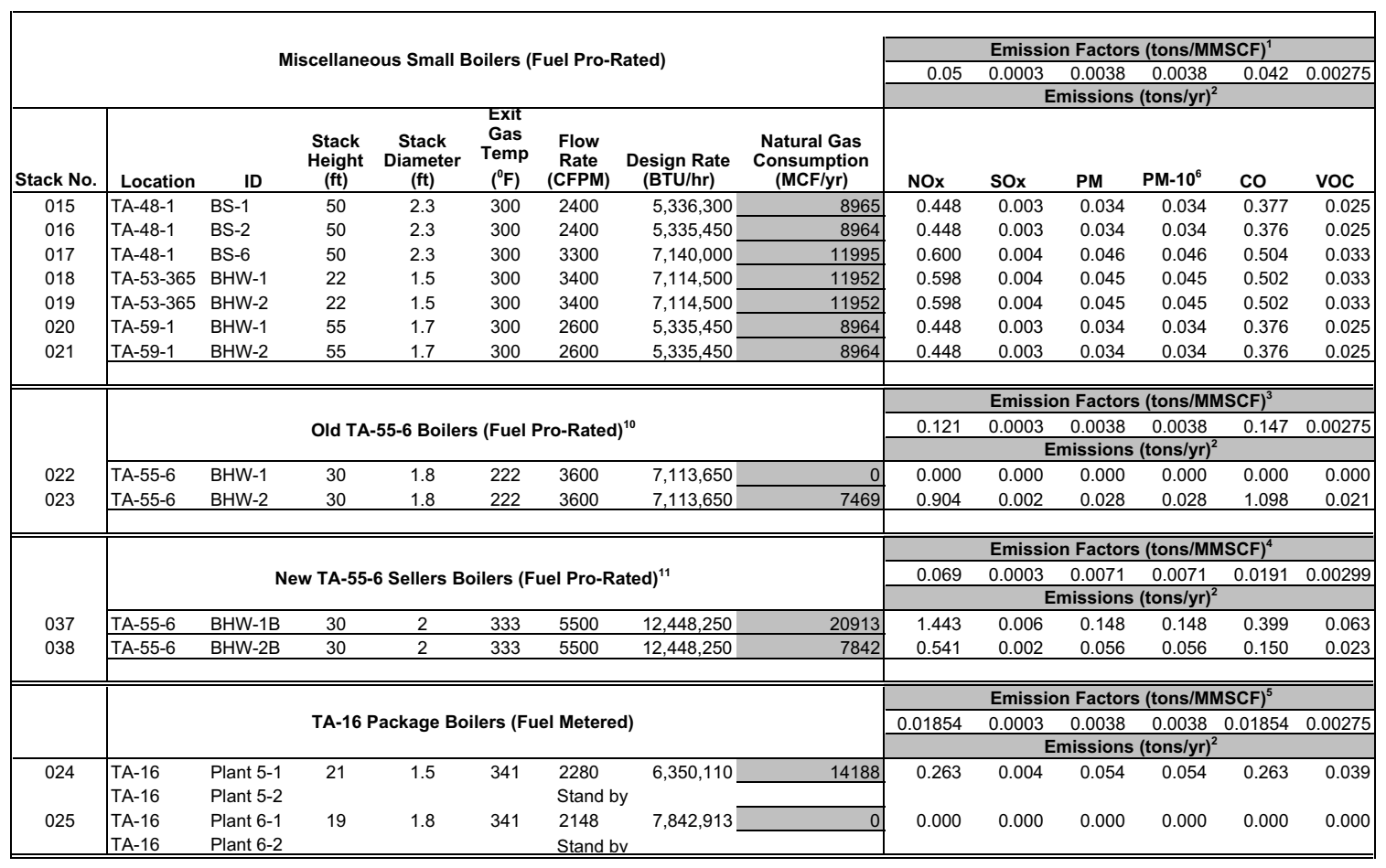

${ }^{1}$ AP-42, 7/98, Section 1.4, Natural Gas Combustion , Small Boilers

${ }^{2}$ Natural gas: Sulfur content is $<0.1 \%$ and ash content is non-applicable.

$$
\begin{array}{ll}
\text { Heat Value: } & 1030 \mathrm{BTU} / \mathrm{scf} \\
\text { Conversions: } & 8760 \mathrm{hr} / \mathrm{yr}
\end{array}
$$

${ }^{3}$ Stack test on 3/00 for NOx and CO. Otherwise, Emission factors obtained from AP-42, 7/98, Section 1.4, Natural Gas Combustion

Small Boilers.

${ }^{4}$ AP-42, 7/98, Section 1.4, Natural Gas Combustion , Small Boilers for SOx. Stack test on 3/00 for NOx. Otherwise, Emission factors from

Sellers Engineering Co.

${ }^{5}$ AP-42, 7/98, Section 1.4, Natural Gas Combustion , Small Boilers; Emission factors for NOx and CO from Sellers Engineering Co.

${ }^{6}$ Emission factors for natural gas of PM-10 are roughly equal to those of PM, Natural Gas Combustion, Table 1.4-2

${ }^{*}$ Assume all SOx is converted to sulfuric acid

${ }^{7}$ AP-42, Table 1.4-3, July 1998

${ }^{8}$ AP-42, Table 1.4-4, July 1998

${ }^{9}$ AP-42, Table 1.4-2, July 1998

${ }^{10}$ Old TA-55-4 Boilers were replaced with new Sellers Low-NOx Boilers. BHW-1 was replaced in 1998. BHW-2 was replaced in Oct. 2001. Fuel to BHW-2 is pro-rated to reflect partial year operations.

${ }^{11}$ New Sellers Boiler (TA-55-6 BHW-2B) was installed on Oct. 1, 2001. Fuel is pro-rated to reflect 3 months of operation.

${ }^{12}$ EPCRA PAC Guidance Document, Table 2-3 
2001 Emissions Inventory Report-Paper Shredder

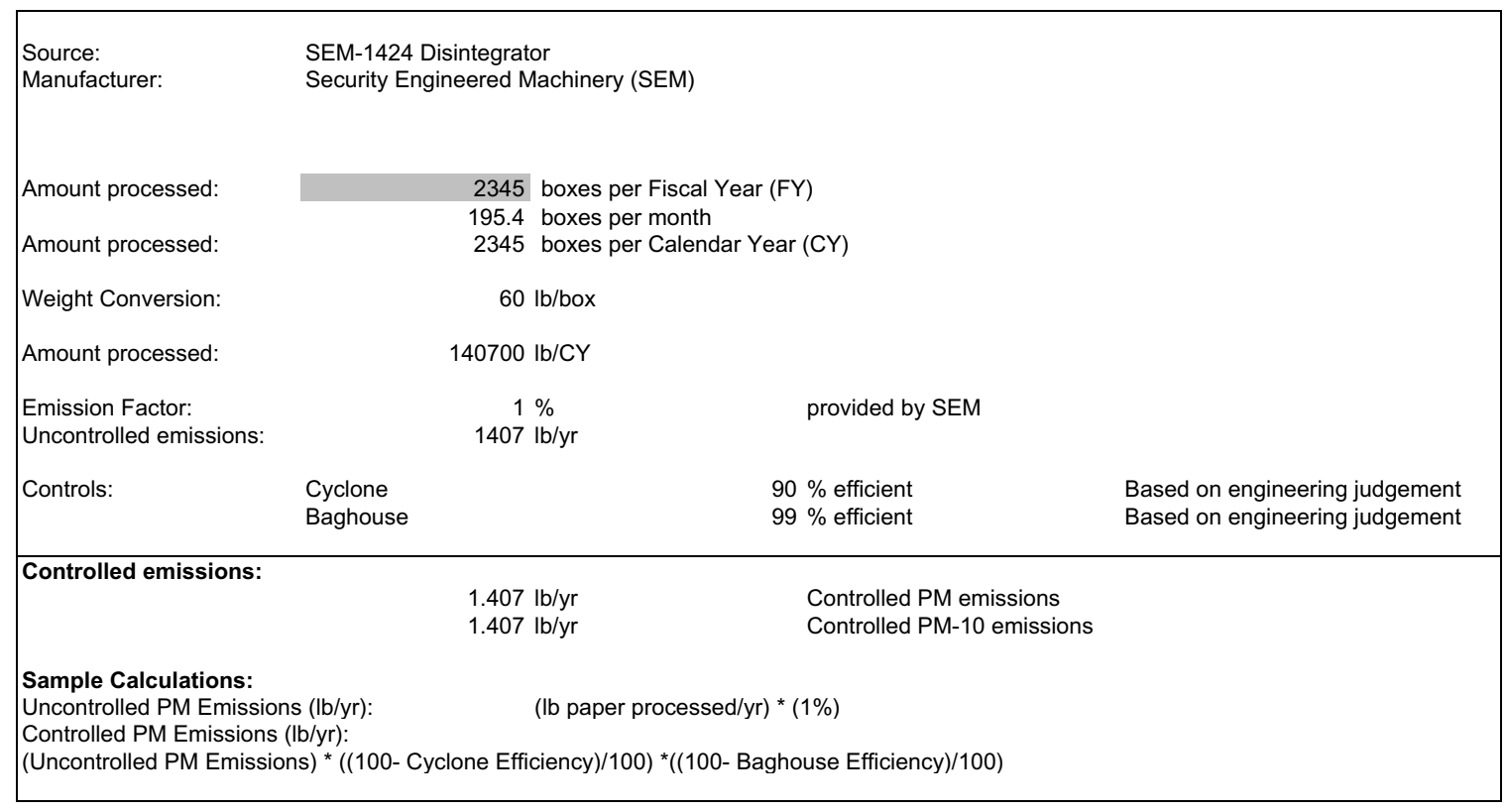


2001 Emissions Inventory Report-Rock Crusher

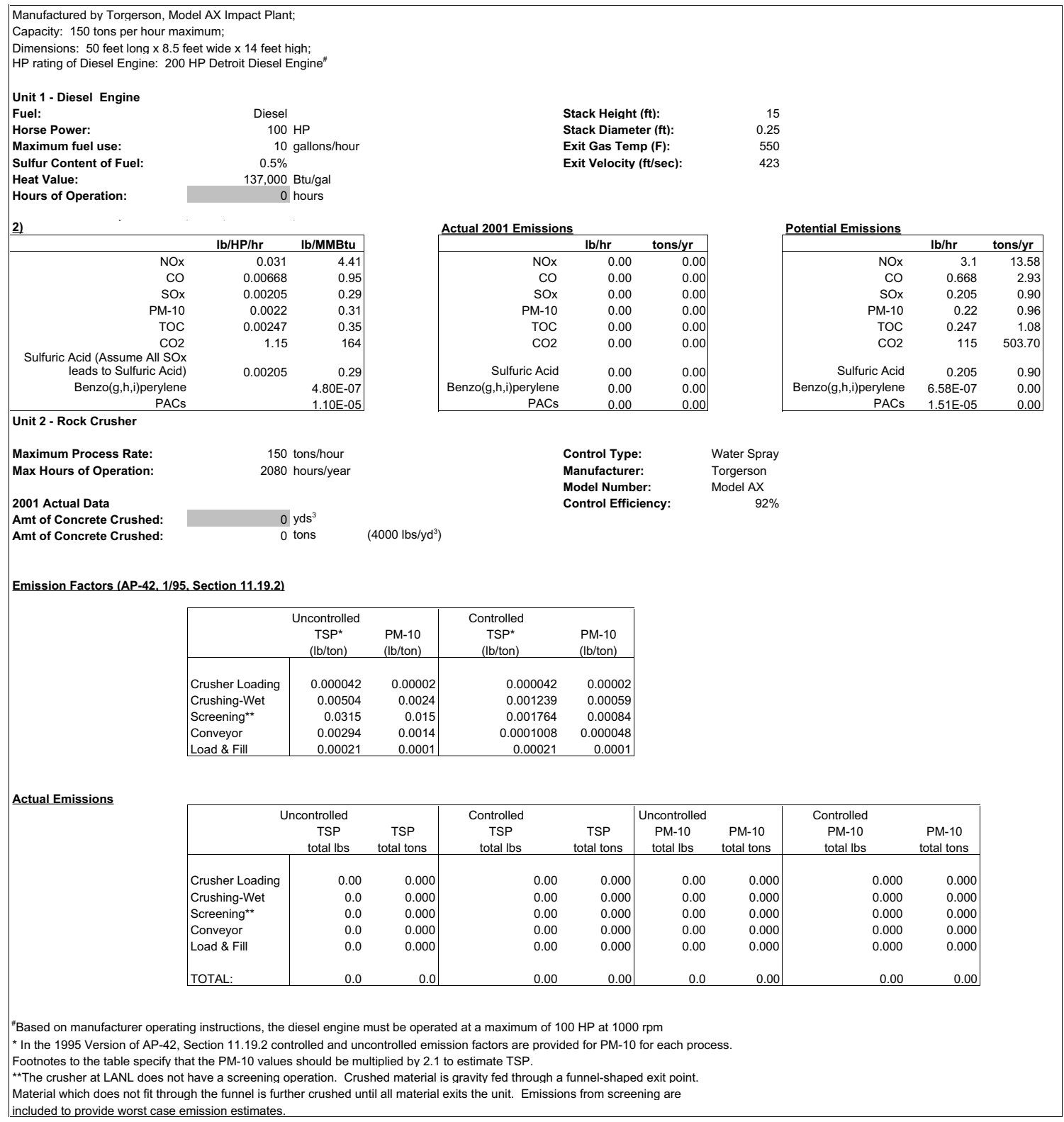




\section{Air Curtain Destructors Burn Emissions}

\begin{tabular}{|c|c|c|c|c|c|c|c|c|}
\hline S-127 Air Curtain Destructor & $\begin{array}{c}\text { Total Wood Burned } \\
\text { (ton) })^{2}\end{array}$ & NOx & co & sox & TSP & PM-10 & $\mathrm{CO}_{2}$ & voc \\
\hline Emissions Factors (Burn) (Ib/ton) ${ }^{1}$ & 127 & 2 & 1.4 & 0.0075 & 0.2 & 0.15 & 1.4 & 3.8 \\
\hline \multicolumn{9}{|l|}{ S-127 Surface Air Curtain Destructor } \\
\hline Emissions (lb/yr) & & 254.5 & 178.2 & 1.0 & 25.5 & 19.1 & 178.2 & 483.6 \\
\hline Emissions Total (ton/yr) & & 0.127 & 0.089 & 0.000 & 0.013 & 0.010 & 0.089 & 0.242 \\
\hline T-350 Trench Burner \# 1 & $\begin{array}{c}\begin{array}{c}\text { Total Wood Burned } \\
\text { (ton) }\end{array} \\
\end{array}$ & NOx & co & sox & TSP & PM-10 & $\mathrm{CO}_{2}$ & voc \\
\hline Emissions Factors (Burn) (Ib/ton) ${ }^{1}$ & 597 & 2 & 1.4 & 0.0075 & 2 & 1.5 & 1.4 & 3.8 \\
\hline
\end{tabular}

\begin{tabular}{|c|c|c|c|c|c|c|c|c|}
\hline \multirow{2}{*}{\multicolumn{2}{|c|}{\begin{tabular}{r|} 
Emissions (lb/yr) \\
Emissions Total (ton/yr)
\end{tabular}}} & \begin{tabular}{|l|l|}
1193.6 \\
\end{tabular} & 835.5 & $\begin{array}{r}4.5 \\
\end{array}$ & 1193.6 & \begin{tabular}{|l|}
895.2 \\
\end{tabular} & \begin{tabular}{|l|}
835.5 \\
\end{tabular} & 2267.9 \\
\hline & & $\begin{array}{l}0.597 \\
\end{array}$ & 0.418 & 0.002 & $\begin{array}{l}0.597 \\
\end{array}$ & 0.448 & 0.418 & 1.134 \\
\hline T-350 Trench Burner \# 2 & \begin{tabular}{|c|}
$\begin{array}{c}\text { Total Wood Burned } \\
\text { (ton) })^{2}\end{array}$ \\
\end{tabular} & & & & & & & \\
\hline Emissions (lb/yr) & 492 & \begin{tabular}{|c|}
983.6 \\
\end{tabular} & 688.5 & 3.7 & $\begin{array}{l}983.6 \\
\end{array}$ & 737.7 & 688.5 & 1868.9 \\
\hline Emissions Total (ton/yr) & & 0.492 & 0.344 & 0.002 & 0.492 & 0.369 & 0.344 & 0.934 \\
\hline
\end{tabular}

conversion (lb/ton)

2000

${ }^{1}$ Emissions Factors from Notice of Intent (NOI) application submitted to NMED on 05/07/01

${ }^{2}$ Wood totals obtained from air curtain destructor operating logs maintained by FWO.

\begin{tabular}{|c|c|c|c|c|c|c|c|c|c|}
\hline S-127 Air Curtain Destructor & $\begin{array}{l}\text { Diesel Fuel Used } \\
(\mathrm{Gal})^{3}\end{array}$ & NOx & co & sox & TSP & PM-10 & $\mathrm{CO}_{2}$ & Aldehydes & voc \\
\hline Emission Factors (Engine) Ib/hp-hr ${ }^{1}$ & 75 & 0.031 & 0.0067 & 0.0021 & 0.0022 & 0.0022 & 1.15 & 0.00046 & 0.0025 \\
\hline \multicolumn{10}{|l|}{ Surface Unit S-127 John Deere } \\
\hline Emissions (lb/year) ${ }^{2}$ & & 126.4 & 27.3 & 8.6 & 9.0 & 9.0 & 4690.9 & 1.9 & 10.2 \\
\hline Emissions Total Ton/Year & & 0.063 & 0.014 & 0.004 & 0.004 & 0.004 & 2.345 & 0.001 & 0.005 \\
\hline T-350 Air Curtain Destructors & $\begin{array}{l}\text { Diesel Fuel Used } \\
(\text { (Gal) })^{3}\end{array}$ & NOx & co & sox & TSP & PM-10 & $\mathrm{CO}_{2}$ & Aldehydes & voc \\
\hline Emission Factors (Engine) Ib/hp-hr ${ }^{1}$ & 446 & 0.031 & 0.0067 & 0.0021 & 0.0022 & 0.0022 & 1.15 & 0.00046 & 0.0025 \\
\hline \multicolumn{10}{|l|}{ Trench Unit \# 1 T-350 John Deere } \\
\hline Emissions (lb/year) & & 752.0 & 162.5 & 50.9 & 53.4 & 53.4 & 27895.0 & 11.2 & 60.6 \\
\hline Emissions Total Ton/Year & & 0.376 & 0.081 & 0.025 & 0.027 & 0.027 & 13.947 & 0.006 & 0.030 \\
\hline \multirow[t]{2}{*}{ Trench Unit \# 2 T-350 John Deere } & $\begin{array}{l}\text { Diesel Fuel Used } \\
(\mathrm{Gall})^{3}\end{array}$ & & & & & & & & \\
\hline & 267 & & & & & & & & \\
\hline Emissions (lb/year) ${ }^{2}$ & & 450.2 & 97.3 & 30.5 & 31.9 & 31.9 & 16699.4 & 6.7 & 36.3 \\
\hline Emissions Total Ton/Year & & 0.225 & 0.049 & 0.015 & 0.016 & 0.016 & 8.350 & 0.003 & 0.018 \\
\hline
\end{tabular}

\begin{tabular}{|l|r|}
\hline heat value $(\mathrm{BTU} / \mathrm{gal})$ & 138,500 \\
\hline conversion $\left(\mathrm{hp}{ }^{*} \mathrm{sec} / \mathrm{BTU}\right)$ & 1.414 \\
\hline conversion $(\mathrm{min} / \mathrm{sec})$ & 0.017 \\
\hline conversion $(\mathrm{hr} / \mathrm{min})$ & 0.017 \\
\hline conversion $(\mathrm{lb} / \mathrm{ton})$ & 2000 \\
\hline
\end{tabular}

${ }^{1}$ Emissions Factors from Notice of Intent (NOI) application submitted to NMED on 05/07/01

Sample Calculation: $\left(1.341 * 10^{-3} \mathrm{hp}^{*} \mathrm{sec} / 9.486^{*} 10^{-4} \mathrm{btu}\right){ }^{*}(1 \mathrm{~min} / 60 \mathrm{sec}) *(1 \mathrm{hr} / 60 \mathrm{~min}) * 138500 \mathrm{btu} / \mathrm{gal}{ }^{*} 75 \mathrm{gal} * 0.031 \mathrm{lb} / \mathrm{hp}-\mathrm{hr}=126.4 \mathrm{lb} / \mathrm{yr}$

${ }^{3}$ Heat Value of diesel fuel $=138,500 \mathrm{btu} / \mathrm{gal}$. Fuel values obtained from Robert Garcia of ESA-WMM.

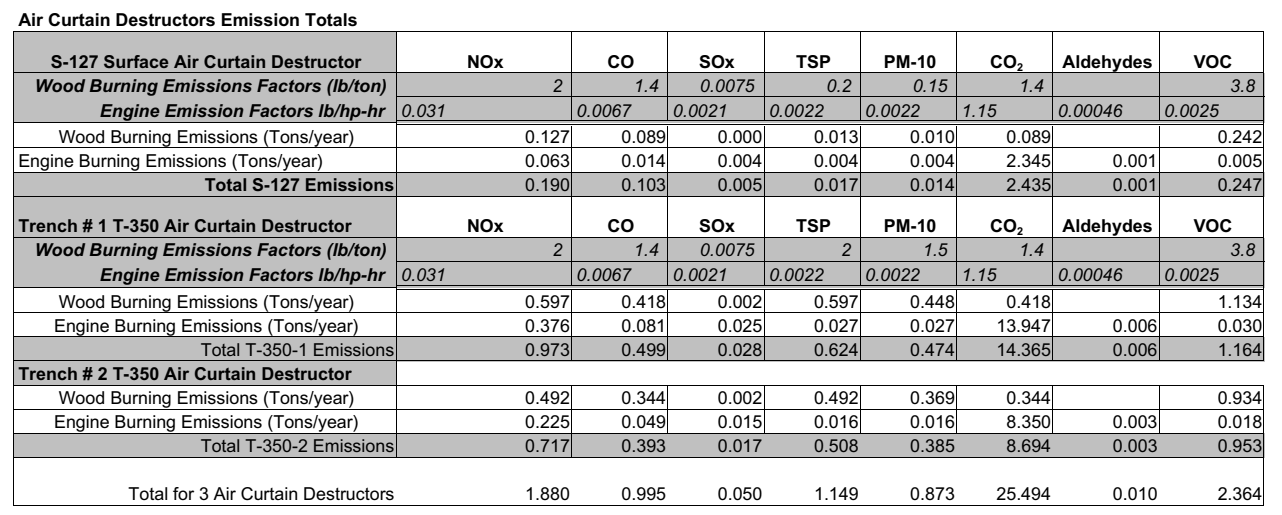

${ }^{1}$ Emissions Factors from Notice of Intent (NOI) application submitted to NMED on 05/07/01 
Attachment C. Emissions Inventory Submittal to NMED

\section{LOS ALAMOS NATIONAL LABORATORY'S 2001 EMISSIONS INVENTORY}

Submitted as Required by:

Title 20, Chapter 2, Part 73 of the New Mexico Administrative Code

Prepared by:

The University of California

For:

The National Nuclear Security Administration of the United States Department of Energy

Information Contacts:

Margie Stockton, (505) 667-9359

Jackie Hurtle, (505) 665-4380

\section{Certification Statement}

I, James Lee McAtee, hereby certify on behalf of Los Alamos National Laboratory and the University of California, that the information and statements contained in this Emissions Inventory report are true and accurate to the best of my knowledge and belief.

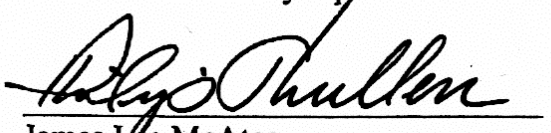

James Ife McAtee

Deputy Division Leader

Environmental Safety and Health Division

University of California

Los Alamos National Laboratory

(505) 667-4218

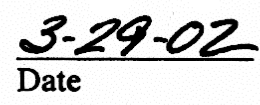




\begin{tabular}{|c|c|c|c|c|c|c|c|c|c|c|c|}
\hline County & $\begin{array}{l}\text { County } \\
\text { FIPS }\end{array}$ & $\begin{array}{c}\text { AFS/ } \\
\text { NEDS } \\
\text { Plant ID }\end{array}$ & $\begin{array}{c}\text { Inventory } \\
\text { Year } \\
\text { (YYYY) }\end{array}$ & $\begin{array}{c}\text { Air } \\
\text { Program } \\
\text { Status }\end{array}$ & SIC & Company Name & Street Line 1 & Street Name 2 & City & State & Zip Code \\
\hline $\begin{array}{l}\text { Los } \\
\text { Alamos }\end{array}$ & 028 & 0001 & 2001 & & 9711 & 1 Los Alamos National Laboratory & $\begin{array}{l}\text { P.O. Box } 1663 \text {, Air } \\
\text { Quality Group }\end{array}$ & Mail Stop J978 & Los Alamos & NM & 87545- \\
\hline
\end{tabular}

\begin{tabular}{|c|c|c|c|c|c|c|c|c|c|c|}
\hline $\begin{array}{c}\text { Contact Person } \\
\text { Name }\end{array}$ & $\begin{array}{c}\text { Contact Person } \\
\text { Phone }\end{array}$ & $\begin{array}{c}\text { Contact Person E- } \\
\text { mail }\end{array}$ & $\begin{array}{l}\text { UTM } \\
\text { Zone }\end{array}$ & UTMH & UTMV & $\begin{array}{c}\begin{array}{c}\text { Elevation } \\
(\mathrm{ft})\end{array} \\
\end{array}$ & Street Line 1 & City & Permit Number & strClass \\
\hline Hurtle Jackie & 5056654380 & jhurtle@lanl.gov & 13 & 381.19 & 3970.3 & 7380 & $\begin{array}{l}1 \mathrm{Mi} \mathrm{S} \text {. of } \\
\text { Los Alamos }\end{array}$ & Los Alamos & $\begin{array}{l}\text { 1081M1R3, 02195, } \\
\text { 02195B, 0632, } \\
\text { 0634M2, 0635, } \\
0636,2597\end{array}$ & A \\
\hline
\end{tabular}


LANL Point Activity 2001

\begin{tabular}{|c|c|c|c|c|c|c|c|c|c|c|c|c|c|}
\hline $\begin{array}{c}\text { County } \\
\text { FIPs } \\
\text { Code } \\
\end{array}$ & $\begin{array}{c}\text { AFS/NEDS } \\
\text { Plant ID } \\
\end{array}$ & $\begin{array}{c}\text { Inventory } \\
\text { Year } \\
\text { (YYYY) }\end{array}$ & Company Name & Description & \begin{tabular}{|c|} 
AIRS \\
Point ID \\
\end{tabular} & \begin{tabular}{|} 
AIRS \\
Stack ID
\end{tabular} & $\begin{array}{c}\text { Segment } \\
\text { ID }\end{array}$ & $\begin{array}{l}2001 \text { Actual } \\
\text { Throughput }\end{array}$ & $\begin{array}{l}\text { Throughput } \\
\text { Unit } \\
\text { Numerator }\end{array}$ & \begin{tabular}{|l|} 
Max Operating \\
Rate Per Hour
\end{tabular} & Material & $\begin{array}{c}\text { Material } \\
\text { I/O }\end{array}$ & strClass \\
\hline 028 & 0001 & 2001 & Los Alamos National Laboratory & BE Machining TA 3-39 & 001 & 001 & 01 & \multicolumn{2}{|c|}{ 0 Unknown } & 0000000 & & & A \\
\hline 028 & 0001 & 2001 & Los Alamos National Laboratory & TA 3 Power Plant Boilers (3) & 002 & 002 & 01 & \multicolumn{2}{|c|}{737 E6FT3S } & 0000006 & & & A \\
\hline 028 & 0001 & 2001 & Los Alamos National Laboratory & TA-21 Boilers (3) & 004 & 004 & 01 & \multicolumn{2}{|c|}{37 E6FT3S } & 0000033 & Nat gas & & A \\
\hline 028 & 0001 & 2001 & Los Alamos National Laboratory & Boiler - NOT BUILT & 005 & 005 & 01 & \multicolumn{2}{|c|}{0 E6FT3S } & 0000000 & & & A \\
\hline 028 & 0001 & 2001 & Los Alamos National Laboratory & BE Machining TA 35-213 & 006 & 006 & 01 & \multirow{2}{*}{\multicolumn{2}{|c|}{$\begin{array}{l}0 \text { Unknown } \\
0 \text { Unknown }\end{array}$}} & 0000000 & & & A \\
\hline 028 & 0001 & 2001 & Los Alamos National Laboratory & BE Machining TA 3-141 & 007 & 007 & 01 & & & 0000000 & & & A \\
\hline 028 & 0001 & 2001 & Los Alamos National Laboratory & BE Machining TA 3-102 & 008 & 008 & 01 & \multicolumn{2}{|c|}{$\begin{array}{l}0 \text { Unknown } \\
0 \text { Unknown }\end{array}$} & 0000000 & & & A \\
\hline 028 & 0001 & 2001 & Los Alamos National Laboratory & BE Shop TA 3-35 NOT BUILT & 009 & 009 & 01 & \multicolumn{2}{|c|}{0 Unknown } & 0000000 & & & A \\
\hline 028 & 0001 & 2001 & Los Alamos National Laboratory & BE Cut \& Bead Dress TA 55-4 & 010 & 010 & 01 & \multicolumn{2}{|c|}{1100 LB } & 0000000 & & & A \\
\hline 028 & 0001 & 2001 & Los Alamos National Laboratory & North & 011 & 011 & 01 & \multicolumn{2}{|c|}{1100 LB } & 0000000 & & & A \\
\hline 028 & 0001 & 2001 & Los Alamos National Laboratory & Asphalt Plant TA 3-73 & 013 & 013 & 01 & \multicolumn{2}{|c|}{2576 TON } & 0000000 & Asphalt & & A \\
\hline 028 & 0001 & 2001 & Los Alamos National Laboratory & Caterpillar Water Pump & 014 & 014 & 01 & \multicolumn{2}{|c|}{ 12.2 E6FT3S } & 0000005 & Nat. Gas & & A \\
\hline 028 & 0001 & 2001 & Los Alamos National Laboratory & Boiler TA-48-1 BS-1 & 015 & 015 & 01 & \multicolumn{2}{|c|}{8.9 E6FT3S } & & Nat. Gas & & A \\
\hline 028 & 0001 & 2001 & Los Alamos National Laboratory & Boiler TA-48-1 BS-2 & 016 & 016 & 01 & \multicolumn{2}{|c|}{8.9 E6FT3S } & & Nat. Gas & & A \\
\hline 028 & 0001 & 2001 & Los Alamos National Laboratory & Boiler TA-48-1 BS-6 & 017 & 017 & 01 & \multicolumn{2}{|c|}{ 11.9 E6FT3S } & & Nat. Gas & & A \\
\hline 028 & 0001 & 2001 & Los Alamos National Laboratory & Boiler TA-53-365 BHW-1 & 018 & 018 & 01 & \multirow{2}{*}{\multicolumn{2}{|c|}{$\begin{array}{l}11.9 \text { E6FT3S } \\
11.9 \text { E6FT3S }\end{array}$}} & & Nat. Gas & & A \\
\hline 028 & 0001 & 2001 & Los Alamos National Laboratory & Boiler TA-53-365 BHW-2 & 019 & 019 & 01 & & & & Nat. Gas & & A \\
\hline 028 & 0001 & 2001 & Los Alamos National Laboratory & Boiler TA-59-1 BHW-1 & 020 & 020 & 01 & \multicolumn{2}{|c|}{$\begin{array}{r}11.9 \text { E6FT3S } \\
8.9 \text { E6FT3S }\end{array}$} & & Nat. Gas & & A \\
\hline 028 & 0001 & 2001 & Los Alamos National Laboratory & Boiler TA-59-1 BHW-2 & 021 & 021 & 01 & \multicolumn{2}{|c|}{8.9 E6FT3S } & & Nat. Gas & & A \\
\hline 028 & 0001 & 2001 & Los Alamos National Laboratory & Boiler TA-55-6 BHW-1 & 022 & 022 & 01 & \multicolumn{2}{|c|}{0 E6FT3S } & & Nat. Gas & & A \\
\hline 028 & 0001 & 2001 & Los Alamos National Laboratory & Boiler TA-55-6 BHW-2 & 023 & 023 & 01 & \multicolumn{2}{|c|}{7.5 E6FT3S } & & Nat. Gas & & A \\
\hline 028 & 0001 & 2001 & Los Alamos National Laboratory & Boiler \& Backup TA-16 Plant 5 & 024 & 024 & 01 & \multicolumn{2}{|c|}{ 14.2 E6FT3S } & & Nat. Gas & & A \\
\hline 028 & 0001 & 2001 & Los Alamos National Laboratory & Boiler \& Backup TA-16 Plant 6 & 025 & 025 & 01 & \multirow{2}{*}{\multicolumn{2}{|c|}{$\begin{array}{l}0 \text { E6FT3S } \\
0 \text { tons }\end{array}$}} & & Nat. Gas & & A \\
\hline 028 & 0001 & 2001 & Los Alamos National Laboratory & Rock Crusher & 026 & 026 & 01 & & & & Rock & & A \\
\hline 028 & 0001 & 2001 & Los Alamos National Laboratory & Paper Shredder TA-52-11 & 027 & 027 & 01 & \multicolumn{2}{|c|}{$140,700 \mathrm{lb}$} & 0 & Paper & & A \\
\hline 028 & 0001 & 2001 & Los Alamos National Laboratory & Degreaser TA-55-4 & 028 & 028 & 01 & 82 & & & Solvent & & A \\
\hline 028 & 0001 & 2001 & Los Alamos National Laboratory & Degreaser TA-46-24 & 029 & 029 & 01 & & L & & & & A \\
\hline 028 & 0001 & 2001 & Los Alamos National Laboratory & Degreaser TA-49-24 & 030 & 030 & 01 & & L & & & & A \\
\hline 028 & 0001 & 2001 & Los Alamos National Laboratory & R\&D Activities Labwide & 031 & 031 & 01 & & tons & & & & A \\
\hline 028 & 0001 & 2001 & Los Alamos National Laboratory & Edgemoor Iron Works Boiler & 032 & 032 & 01 & 223.1 & E6FT3S & 0.184 & Nat. Gas & & A \\
\hline 028 & 0001 & 2001 & Los Alamos National Laboratory & Edgemoor Iron Works Boiler & 033 & 033 & 01 & 370.0 & E6FT3S & 0.184 & Nat. Gas & & A \\
\hline 028 & 0001 & 2001 & Los Alamos National Laboratory & Edgemoor Iron Works Boiler & 034 & 034 & 01 & 295.6 & E6FT3S & 0.184 & Nat. Gas & & A \\
\hline 028 & 0001 & 2001 & Los Alamos National Laboratory & Tank TA-03-026 (No. 2 fuel oil) & 035 & 035 & 01 & 48,784 & Gallons & & Fuel Oil & & A \\
\hline 028 & 0001 & 2001 & Los Alamos National Laboratory & Tank TA-03-779 (No. 2 fuel oil) & 036 & 036 & 01 & 73,176 & Gallons & & Fuel Oil & & A \\
\hline 028 & 0001 & 2001 & Los Alamos National Laboratory & Sellers boiler TA-55-6 BHW-1B & 037 & 037 & 01 & 20.9 & E6FT3S & 0.012 & Nat. Gas & & A \\
\hline 028 & 0001 & 2001 & Los Alamos National Laboratory & Sellers boiler TA-55-6 BHW-2B & 038 & 038 & 01 & & E6FT3S & 0.012 & Nat. Gas & & A \\
\hline 028 & 0001 & 2001 & Los Alamos National Laboratory & Air Curtain Destructor S-127 & New-1 & New-1 & 01 & & tons & 20 & Wood & & \\
\hline 028 & 0001 & 2001 & Los Alamos National Laboratory & Air Curtain Destructor T-350-1 & New-2 & New-2 & 01 & & tons & 20 & Wood & & \\
\hline 028 & 0001 & 2001 & Los Alamos National Laboratory & Air Curtain Destructor T-350-2 & & & & & & & & & \\
\hline
\end{tabular}


LANL Emission Units 2001

\begin{tabular}{|c|c|c|c|c|c|c|c|c|c|c|c|c|c|}
\hline $\begin{array}{c}\text { County } \\
\text { FIPS }\end{array}$ & $\begin{array}{c}\text { AFS/NEDS } \\
\text { Plant ID }\end{array}$ & $\begin{array}{c}\text { Inventory } \\
\text { Year } \\
\text { (YYYY) }\end{array}$ & Company Name & $\begin{array}{l}\text { AlRS } \\
\text { Point } \\
\text { ID }\end{array}$ & Description & $\begin{array}{c}\text { Design } \\
\text { Capactiy }\end{array}$ & $\begin{array}{c}\text { Design } \\
\text { Capacity Unit } \\
\text { Numerator }\end{array}$ & \begin{tabular}{|c|} 
Design \\
Capacity Unit \\
Denominator
\end{tabular} & $\begin{array}{c}\text { Max } \\
\text { Nameplate } \\
\text { Capacity }\end{array}$ & $\begin{array}{l}\text { Installation } \\
\text { Date }\end{array}$ & $\begin{array}{c}\text { Removal } \\
\text { Date }\end{array}$ & $\begin{array}{l}\text { Shut } \\
\text { Down? }\end{array}$ & strClass \\
\hline 028 & 0001 & 2001 & 1 Los Alamos National Laboratory & 001 & Be MACHINING TA-3 BLDG 39 & 0 & & & 0 & 01-Jan-85 & & FALSE & A \\
\hline 028 & 0001 & 2001 & 1 Los Alamos National Laboratory & 002 & TA3-22 BoilerS (3 Each) & 178.5 & E6BTU & HR & 210 & & & FALSE & A \\
\hline 028 & 0001 & 2001 & 1 Los Alamos National Laboratory & 003 & TA16 Boiler (3 Each)- REMOVED & & E6BTU & HR & 96 & 01-Jan-50 & 01-Jan-97 & TRUE & A \\
\hline 028 & 0001 & 2001 & 1 Los Alamos National Laboratory & 004 & STEAM Plant Boiler TA21 BLDG357 (3) & & E6BTU & HR & 36 & 01-Jan-83 & & FALSE & \\
\hline 028 & 0001 & 2001 & 1 Los Alamos National Laboratory & 005 & TD SITE Boiler NOT BUILT & & E6BTU & HR & 0 & & & TRUE & \\
\hline 028 & 0001 & 2001 & 1 Los Alamos National Laboratory & 006 & Be MACHINING TA35 BLDG213 & 0 & & & 0 & 26-Dec-85 & & FALSE & A \\
\hline 028 & 0001 & 2001 & 1 Los Alamos National Laboratory & 007 & Be MACHINING TA3 BLDG 141 & 0 & & & 10000 & 19-Mar-85 & & FALSE & A \\
\hline 028 & 0001 & 2001 & 1 Los Alamos National Laboratory & 008 & Be MACHINING TA3 BLDG 102 & 0 & & & 0 & 19-Mar-86 & & FALSE & A \\
\hline 028 & 0001 & 2001 & 1 Los Alamos National Laboratory & 009 & Be SHOP TA3-35 NOT BUILT & 0 & & & 0 & & & TRUE & A \\
\hline 028 & 0001 & 2001 & 1 Los Alamos National Laboratory & 010 & Be CUTTING \& BEAD Dressing TA-55-4 & 0 & & & 1100 & 01-Jan-78 & & FALSE & A \\
\hline 028 & 0001 & 2001 & 1 Los Alamos National Laboratory & 011 & METALLOGRAPHY TA55-4 NORTH STACK & 0 & & & 1100 & 01-Jan-78 & & FALSE & A \\
\hline 028 & 0001 & 2001 & 1 Los Alamos National Laboratory & 012 & Not Built - SOLID WASTE FIRED Boiler & 0 & & & 0 & & & TRUE & A \\
\hline 028 & 0001 & 2001 & 1 Los Alamos National Laboratory & 013 & Asphalt Plant TA-3-73 & & TON & HR & 60 & 01-Jan-60 & & FALSE & A \\
\hline 028 & 0001 & 2001 & 1 Los Alamos National Laboratory & 014 & Caterpillar HCR TA SI PUMP Engine & 700 & $\mathrm{HP}$ & & 700 & 01-Jan-82 & & FALSE & \\
\hline 028 & 0001 & 2001 & 1 Los Alamos National Laboratory & 015 & Boiler (TA-48-1) BS-1 & & E6BTU & HR & 6.3 & 01-Aug-87 & & FALSE & A \\
\hline 028 & 0001 & 2001 & 1 Los Alamos National Laboratory & 016 & Boiler (TA-48-1) BS-2 & & E6BTU & HR & 6.3 & 01-Oct-76 & & FALSE & \\
\hline 028 & 0001 & 2001 & 1 Los Alamos National Laboratory & 017 & Boiler (TA-48-1) BS-6 & & E6BTU & HR & 8.4 & 01-Oct-94 & & FALSE & A \\
\hline 028 & 0001 & 2001 & 1 Los Alamos National Laboratory & 018 & Boiler (TA-53-365) BHW-1 & & E6BTU & HR & 8.4 & 01-Jan-88 & & FALSE & A \\
\hline 028 & 0001 & 2001 & 1 Los Alamos National Laboratory & 019 & Boiler (TA-53-365) BHW-2 & & E6BTU & HR & 8.4 & 01-Jan-88 & & FALSE & A \\
\hline 028 & 0001 & 2001 & 1 Los Alamos National Laboratory & 020 & Boiler (TA-59-1) BHW-1 & & E6BTU & HR & 6.3 & 01-Sep-78 & & FALSE & A \\
\hline 028 & 0001 & 2001 & 1 Los Alamos National Laboratory & 021 & Boiler (TA-59-1) BHW-2 & & E6BTU & HR & 6.3 & 01-Oct-94 & & FALSE & A \\
\hline 028 & 0001 & 2001 & 1 Los Alamos National Laboratory & 022 & Boiler (TA-55-6) BHW-1 & & E6BTU & HR & 8.4 & 01-Jan-76 & 01-Oct-98 & TRUE & A \\
\hline 028 & 0001 & 2001 & 1 Los Alamos National Laboratory & 023 & Boiler (TA-55-6) BHW-2 & & E6BTU & HR & 8.4 & 01-Jan-76 & 01-Oct-01 & TRUE & A \\
\hline 028 & 0001 & 2001 & 1 Los Alamos National Laboratory & 024 & Boiler and backup, TA-16, Plant-5 & 12.7 & E6BTU & HR & 15 & 01-Nov-96 & & FALSE & A \\
\hline 028 & 0001 & 2001 & 1 Los Alamos National Laboratory & 025 & Boiler and Backup, Plant 6 (TA-16-1485) & 15.6 & E6BTU & HR & 18.4 & 01-Nov-96 & & FALSE & A \\
\hline 028 & 0001 & 2001 & 1 Los Alamos National Laboratory & 026 & Rock Crusher & & TON & hour & 150 & 01-Jun-98 & & FALSE & A \\
\hline 028 & 0001 & 2001 & 1 Los Alamos National Laboratory & 027 & 11) & 300 & LB & $\mathrm{HR}$ & 300 & 01-Jan-91 & & FALSE & A \\
\hline 028 & 0001 & 2001 & 1 Los Alamos National Laboratory & 028 & Degreaser - cold ultrasonic bath TA-55-4 & 20 & & 0 & 20 & 01-Sep-98 & & FALSE & A \\
\hline 028 & 0001 & 2001 & 1 Los Alamos National Laboratory & 029 & Degreaser - cold ultrasonic bath TA-46-24 & 18 & & 0 & 18 & 03-Jun-00 & 06-Dec-01 & TRUE & A \\
\hline 028 & 0001 & 2001 & 1 Los Alamos National Laboratory & 030 & Degreaser - inhouse cold batch TA-55-4 & 6 & L & 0 & 6 & 01-Dec-99 & 29-Jan-01 & TRUE & A \\
\hline 028 & 0001 & 2001 & 1 Los Alamos National Laboratory & 031 & R \& D activities - Labwide & 0 & & 0 & 0 & 01-Jan-50 & & FALSE & A \\
\hline 028 & 0001 & 2001 & 1 Los Alamos National Laboratory & 032 & Edgemoor Iron Works Boiler & 189.5 & E6BTU & HR & 210 & 01-Jan-50 & & FALSE & A \\
\hline 028 & 0001 & 2001 & 1 Los Alamos National Laboratory & 033 & Edgemoor Iron Works Boiler & 189.5 & E6BTU & HR & 210 & 01-Jan-50 & & FALSE & \\
\hline 028 & 0001 & 2001 & 1 Los Alamos National Laboratory & 034 & Edgemoor Iron Works Boiler & 189.5 & E6BTU & HR & 210 & 01-Jan-52 & & FALSE & A \\
\hline 028 & 0001 & 2001 & 1 Los Alamos National Laboratory & 035 & Tank TA-03-026 (No. 2 fuel oil) & 3770 & BBL & & 3770 & 01-Jan-50 & & FALSE & A \\
\hline 028 & 0001 & 2001 & 1 Los Alamos National Laboratory & 036 & Tank TA-03-779 (No. 2 fuel oil) & 5455 & BBL & & 5455 & 01-Aug-98 & & FALSE & A \\
\hline 028 & 0001 & 2001 & 1 Los Alamos National Laboratory & 037 & Sellers boiler BHW-1B(TA 55, Bldg. PF6) & 12.4 & E6BTU & HR & 14.6 & 01-Oct-98 & & FALSE & A \\
\hline 028 & 0001 & 2001 & 1 Los Alamos National Laboratory & 038 & Sellers boiler BHW-2B(TA 55, Bldg. PF6) & 12.4 & E6BTU & HR & 14.6 & 06-Sep-01 & & FALSE & \\
\hline 028 & 0001 & 2001 & Los Alamos National Laboratory & New-1 & Air Curtain Destructor S-127 & & tons & $\mathrm{hr}$ & 20 & 29-Oct-01 & & FALSE & \\
\hline 028 & 0001 & 2001 & Los Alamos National Laboratory & New-2 & Air Curtain Destructor T-350-1 & & tons & $\mathrm{hr}$ & 20 & 26-Sep-01 & & FALSE & \\
\hline 028 & 0001 & 2001 & Los Alamos National Laboratory & New-3 & Air Curtain Destructor T-350-2 & & tons & $\mathrm{hr}$ & 20 & 11-Oct-01 & & FALSE & A \\
\hline
\end{tabular}




\begin{tabular}{|c|c|c|c|c|c|c|c|c|}
\hline $\begin{array}{l}\text { County } \\
\text { FIPs } \\
\text { Code } \\
\end{array}$ & $\begin{array}{c}\text { AFS/NEDS } \\
\text { Plant ID }\end{array}$ & $\begin{array}{c}\text { Inventory } \\
\text { Year } \\
\text { (YYYY) }\end{array}$ & Company Name & SCC AFS & $\begin{array}{r}\text { Description } \\
\end{array}$ & $\begin{array}{c}\text { AIRS } \\
\text { Point ID } \\
\end{array}$ & $\begin{array}{c}\text { AIRS } \\
\text { Stack ID } \\
\end{array}$ & $\begin{array}{c}\text { Segment } \\
\text { ID }\end{array}$ \\
\hline 028 & 0001 & 2001 & 01 Los Alamos National Laboratory & 30903004 & BE MACHINING TA-3 BLDG 39 & 001 & 001 & 01 \\
\hline 028 & 0001 & 2001 & 01 Los Alamos National Laboratory & 10100601 & EDGEMOOR BLRS 3EA TA3-22 & 002 & 002 & 01 \\
\hline 028 & 0001 & 2001 & 01 Los Alamos National Laboratory & 10100602 & UNION BOILRS 3EA TA16-540 & 003 & 003 & 01 \\
\hline 028 & 0001 & 2001 & 01 Los Alamos National Laboratory & 10100602 & INDUSTRIL BLRS 3 TA21-357 & 004 & 004 & 01 \\
\hline 028 & 0001 & 2001 & 01 Los Alamos National Laboratory & 10100602 & TD SITE - NOT OPERATING & 005 & 005 & 01 \\
\hline 028 & 0001 & 2001 & 01 Los Alamos National Laboratory & 30903004 & BE MACHINING TA35 BLDG213 & 006 & 006 & 01 \\
\hline 028 & 0001 & 2001 & 01 Los Alamos National Laboratory & 30903004 & BE MACHINING TA3 BLDG 141 & 007 & 007 & 01 \\
\hline 028 & 0001 & 2001 & 01 Los Alamos National Laboratory & 30903004 & BE MACHINING TA3 BLDG 102 & 008 & 008 & 01 \\
\hline 028 & 0001 & 2001 & 01 Los Alamos National Laboratory & 30903004 & BE SHOP TA3-35 NOT BUILT & 009 & 009 & 01 \\
\hline 028 & 0001 & 2001 & 01 Los Alamos National Laboratory & 30903004 & BE CUTTING/DRESS TA 55-4 & 010 & 010 & 01 \\
\hline 028 & 0001 & 2001 & 01 Los Alamos National Laboratory & 30900303 & METALLOG \& BE PREP TA55-4 & 011 & 011 & 01 \\
\hline 028 & 0001 & 2001 & 01 Los Alamos National Laboratory & 30500211 & ASPHALT ROTRY DRYR TA3-73 & 013 & 013 & 01 \\
\hline 028 & 0001 & 2001 & 01 Los Alamos National Laboratory & 20200202 & CAT HCR-TA-SI PUMP ENGINE & 014 & 014 & 01 \\
\hline 028 & 0001 & 2001 & 01 Los Alamos National Laboratory & 0 & Boiler (TA-48-1) BS-1 & 015 & 015 & 01 \\
\hline 028 & 0001 & 2001 & 01 Los Alamos National Laboratory & 0 & Boiler (TA-48-1) BS-2 & 016 & 016 & 01 \\
\hline 028 & 0001 & 2001 & 01 Los Alamos National Laboratory & 0 & Boiler (TA-48-1) BS-6 & 017 & 017 & 01 \\
\hline 028 & 0001 & 2001 & 01 Los Alamos National Laboratory & 0 & Boiler (TA-53-365) BHW-1 & 018 & 018 & 01 \\
\hline 028 & 0001 & 2001 & 01 Los Alamos National Laboratory & 0 & Boiler (TA-53-365) BHW-2 & 019 & 019 & 01 \\
\hline 028 & 0001 & 2001 & 01 Los Alamos National Laboratory & 0 & Boiler (TA-59-1) BHW-1 & 020 & 020 & 01 \\
\hline 028 & 0001 & 2001 & 01 Los Alamos National Laboratory & 0 & Boiler (TA-59-1) BHW-2 & 021 & 021 & 01 \\
\hline 028 & 0001 & 2001 & 01 Los Alamos National Laboratory & 0 & Boiler (TA-55-6) BHW-1 & 022 & 022 & 01 \\
\hline 028 & 0001 & 2001 & 01 Los Alamos National Laboratory & 0 & Boiler (TA-55-6) BHW-2 & 023 & 023 & 01 \\
\hline 028 & 0001 & 2001 & 01 Los Alamos National Laboratory & 0 & Boiler and backup, TA-16, Plant- 5 & 024 & 024 & 01 \\
\hline 028 & 0001 & 2001 & 01 Los Alamos National Laboratory & 0 & Boiler and Backup, Plant 6 (TA-16-1485) & 025 & 025 & 01 \\
\hline 028 & 0001 & 2001 & 01 Los Alamos National Laboratory & 0 & Rock Crusher & 026 & 026 & 01 \\
\hline 028 & 0001 & 2001 & 01 Los Alamos National Laboratory & 0 & SEM-1424 Disintegrator paper shredder (TA-52-11) & 027 & 027 & 01 \\
\hline 028 & 0001 & 2001 & 01 Los Alamos National Laboratory & 0 & Degreaser - cold ultrasonic bath TA-55-4 & 028 & 028 & 01 \\
\hline 028 & 0001 & 2001 & 01 Los Alamos National Laboratory & 0 & Degreaser - cold ultrasonic bath TA-46-24 & 029 & 029 & 01 \\
\hline 028 & 0001 & 2001 & 01 Los Alamos National Laboratory & 0 & Degreaser - inhouse cold batch TA-46-24 & 030 & 030 & 01 \\
\hline 028 & 0001 & 2001 & 01 Los Alamos National Laboratory & 0 & R \& D activities - Labwide & 031 & 031 & 01 \\
\hline 028 & 0001 & 2001 & 01 Los Alamos National Laboratory & 10100601 & Edgemoor Iron Works Boiler & 032 & 032 & 01 \\
\hline 028 & 0001 & 2001 & 01 Los Alamos National Laboratory & 10100601 & Edgemoor Iron Works Boiler & 033 & 033 & 01 \\
\hline 028 & 0001 & 2001 & 01 Los Alamos National Laboratory & 10100601 & Edgemoor Iron Works Boiler & 034 & 034 & 01 \\
\hline 028 & 001 & 2001 & 01 Los Alamos National Laboratory & & Tank TA-03-026 (No. 2 fuel oil) & 035 & 035 & 01 \\
\hline 028 & 001 & 2001 & 01 Los Alamos National Laboratory & & Tank TA-03-779 (No. 2 fuel oil) & 036 & 036 & 01 \\
\hline 028 & 0001 & 2001 & 01 Los Alamos National Laboratory & 10100602 & Sellers boiler BHW-1B(TA 55, Bldg. PF6) & 037 & 037 & 01 \\
\hline 028 & 0001 & 2001 & 01 Los Alamos National Laboratory & 10100602 & Sellers boiler BHW-2B(TA 655, Bldg. PF6) & 038 & 038 & 01 \\
\hline 028 & 0001 & 2001 & 01 Los Alamos National Laboratory & & Air Curtain Destructor S-127 & New-1 & New-1 & 01 \\
\hline 028 & 0001 & 2001 & 01 Los Alamos National Laboratory & & Air Curtain Destructor T-350-1 & New-2 & New-2 & 01 \\
\hline 028 & 0001 & 2001 & 1 Los Alamos National Laboratory & & Air Curtain Destructor T-350-2 & New-3 & New-3 & 01 \\
\hline
\end{tabular}


LANL 2001 Emission Process Information

\begin{tabular}{|c|c|c|c|c|c|c|c|c|c|c|c|}
\hline $\begin{array}{c}\text { Winter } \\
\text { Throughput } \\
\text { PCT }\end{array}$ & $\begin{array}{c}\text { Spring } \\
\text { Throughput } \\
\text { PCT }\end{array}$ & $\begin{array}{c}\text { Summer } \\
\text { Throughput } \\
\text { PCT }\end{array}$ & $\begin{array}{c}\text { Fall } \\
\text { Throughput } \\
\text { PCT }\end{array}$ & $\begin{array}{c}\text { Annual Avg } \\
\text { Hours Per } \\
\text { Day }\end{array}$ & $\begin{array}{c}\text { Annual Avg } \\
\text { Days Per } \\
\text { Week }\end{array}$ & $\begin{array}{l}\text { Annual Avg } \\
\text { Weeks Per } \\
\text { Year } \\
\end{array}$ & $\begin{array}{c}\text { Annual Avg } \\
\text { Hours Per } \\
\text { Year }\end{array}$ & $\begin{array}{c}\text { Heat } \\
\text { Content }\end{array}$ & $\begin{array}{c}\text { Sulfur } \\
\text { Content }\end{array}$ & $\begin{array}{c}\text { Ash } \\
\text { Content }\end{array}$ & strClass \\
\hline 25 & 25 & 25 & 25 & 24 & 5 & 52 & 2400 & 0 & 0 & & A \\
\hline 25 & 25 & 25 & 25 & 24 & 7 & 52 & 8760 & 1030 & 0 & & A \\
\hline 0 & 0 & 0 & 0 & 0 & 0 & 0 & 0 & 0 & 0 & & A \\
\hline 25 & 25 & 25 & 25 & 24 & 7 & 52 & 8760 & 1030 & 0 & & A \\
\hline 0 & 0 & 0 & 0 & 0 & 0 & 0 & 0 & 0 & 0 & & A \\
\hline 15 & 20 & 30 & 35 & 24 & 7 & 52 & 1920 & 0 & 0 & & A \\
\hline 25 & 25 & 25 & 25 & 24 & 7 & 52 & 8760 & 0 & 0 & & A \\
\hline 25 & 25 & 25 & 25 & 24 & 7 & 52 & 2400 & 0 & 0 & & A \\
\hline 0 & 0 & 0 & 0 & 0 & 0 & 0 & 0 & 0 & 0 & & A \\
\hline 25 & 25 & 25 & 25 & 24 & 7 & 52 & 8760 & 0 & 0 & & A \\
\hline 25 & 25 & 25 & 25 & 24 & 7 & 52 & 8760 & 0 & 0 & & A \\
\hline 15 & 20 & 35 & 30 & 24 & 7 & 52 & 60 & 0 & 0 & & A \\
\hline 15 & 35 & 35 & 15 & 24 & 7 & 52 & 2400 & 1030 & 0 & & A \\
\hline 40 & 20 & 0 & 40 & 24 & 7 & 33 & 5500 & 1030 & 0 & & A \\
\hline 40 & 20 & 0 & 40 & 24 & 7 & 33 & 5500 & 1030 & 0 & & A \\
\hline 40 & 20 & 0 & 40 & 24 & 7 & 33 & 5500 & 1030 & 0 & & A \\
\hline 40 & 20 & 0 & 40 & 24 & 7 & 33 & 5500 & 1030 & 0 & & A \\
\hline 40 & 20 & 0 & 40 & 24 & 7 & 33 & 5500 & 1030 & 0 & & A \\
\hline 40 & 20 & 0 & 40 & 24 & 7 & 33 & 5500 & 1030 & 0 & & A \\
\hline 40 & 20 & 0 & 40 & 24 & 7 & 33 & 5500 & 1030 & 0 & & A \\
\hline 0 & 0 & 0 & 0 & 0 & 0 & 0 & 0 & 0 & 0 & & A \\
\hline 40 & 20 & 0 & 40 & 24 & 7 & 33 & 5500 & 1030 & 0 & & A \\
\hline 25 & 25 & 25 & 25 & 24 & 7 & 52 & 8760 & 1030 & 0 & & A \\
\hline 25 & 25 & 25 & 25 & 24 & 7 & 52 & 8760 & 1030 & 0 & & A \\
\hline 0 & 0 & 0 & 0 & 0 & 0 & 0 & 0 & 0 & 0 & & A \\
\hline 25 & 25 & 25 & 25 & 24 & 7 & 52 & 470 & 0 & 0 & & A \\
\hline 25 & 25 & 25 & 25 & 24 & 7 & 52 & 1 & 0 & 0 & & A \\
\hline 0 & 0 & 0 & 0 & 0 & 0 & 0 & 0 & 0 & 0 & & A \\
\hline 0 & 0 & 0 & 0 & 0 & 0 & 0 & 0 & 0 & 0 & & A \\
\hline 25 & 25 & 25 & 25 & 24 & 7 & 52 & 8760 & 0 & 0 & & A \\
\hline 30 & 20 & 20 & 30 & 24 & 7 & 52 & 8760 & 1030 & & & A \\
\hline 30 & 20 & 20 & 30 & 24 & 7 & 52 & 8760 & 1030 & & & A \\
\hline 30 & 20 & 20 & 30 & 24 & 7 & 52 & 8760 & 1030 & & & A \\
\hline 30 & 20 & 20 & 30 & 24 & 7 & 52 & 8760 & & & & A \\
\hline 30 & 20 & 20 & 30 & 24 & 7 & 52 & 8760 & & & & A \\
\hline 40 & 20 & 0 & 40 & 24 & 7 & 33 & 5500 & 1030 & & & A \\
\hline 40 & 20 & 0 & 40 & 24 & 7 & 33 & 5500 & 1030 & & & A \\
\hline 10 & 40 & 10 & 40 & 24 & 5 & 30 & 1500 & & & & \\
\hline 10 & 40 & 10 & 40 & 24 & 5 & 30 & 1500 & & & & \\
\hline 10 & 40 & 10 & 40 & 24 & 5 & 30 & 1500 & & & & \\
\hline
\end{tabular}


LANL 2001 Emission Inventory

Control Equipment Information

\begin{tabular}{|c|c|c|c|c|c|c|c|c|c|c|c|c|}
\hline $\begin{array}{l}\text { County } \\
\text { FIPs } \\
\text { Code } \\
\end{array}$ & $\begin{array}{l}\text { AFS/NEDS } \\
\text { Plant ID }\end{array}$ & $\begin{array}{c}\text { Inventory } \\
\text { Year } \\
\text { (YYYY) }\end{array}$ & Company Name & $\begin{array}{c}\text { AIRS } \\
\text { Point ID } \\
\end{array}$ & $\begin{array}{l}\text { AIRS } \\
\text { Stack } \\
\text { ID }\end{array}$ & $\begin{array}{l}\text { Segment } \\
\text { ID } \\
\end{array}$ & $\begin{array}{l}\text { Pollutant } \\
\text { Code }\end{array}$ & $\begin{array}{c}\text { Primary PCT } \\
\text { Control } \\
\text { Efficiency } \\
\end{array}$ & $\begin{array}{l}\text { Primary } \\
\text { Device } \\
\text { Type } \\
\end{array}$ & $\begin{array}{c}\text { Secondary } \\
\text { Device } \\
\text { Type }\end{array}$ & Description & strClass \\
\hline 028 & 0001 & 2001 & 1 Los Alamos National Laboratory & 001 & 001 & 01 & $\mathrm{BE}$ & 99.9 & 101 & 101 & Cyclone, Baghouse, and HEPA & A \\
\hline 028 & 0001 & 2001 & 1 Los Alamos National Laboratory & 002 & 002 & 01 & $\mathrm{SO} 2$ & 1 & $?$ & & NO EQUIPMENT & A \\
\hline 028 & 0001 & 2001 & 1 Los Alamos National Laboratory & 006 & 006 & 01 & BE & 99.9 & 101 & 101 & HEPA & A \\
\hline 028 & 0001 & 2001 & 1 Los Alamos National Laboratory & 007 & 007 & 01 & $\mathrm{BE}$ & 99.95 & 101 & 101 & HEPA & A \\
\hline 028 & 0001 & 2001 & 1 Los Alamos National Laboratory & 008 & 008 & 01 & $\mathrm{BE}$ & 99.97 & 101 & 101 & HEPA & A \\
\hline 028 & 0001 & 2001 & 1 Los Alamos National Laboratory & 009 & 009 & 01 & $\mathrm{BE}$ & 99.96 & 101 & 101 & HEPA & A \\
\hline 028 & 0001 & 2001 & 1 Los Alamos National Laboratory & 010 & 010 & 01 & AL-PT & 99.95 & 101 & & HEPA & A \\
\hline 028 & 0001 & 2001 & 1 Los Alamos National Laboratory & 010 & 010 & 01 & BE & 99.95 & 101 & 101 & HEPA & A \\
\hline 028 & 0001 & 2001 & 1 Los Alamos National Laboratory & 011 & 011 & 01 & $\mathrm{BE}$ & 99.95 & 101 & 101 & HEPA & A \\
\hline 028 & 0001 & 2001 & 1 Los Alamos National Laboratory & 013 & 013 & 01 & PM10 & & 008 & 002 & cyclone and wet scrubber & A \\
\hline 028 & 0001 & 2001 & 1 Los Alamos National Laboratory & 013 & 013 & 01 & PT & & 008 & 002 & cyclone and wet scrubber & A \\
\hline 028 & 0001 & 2001 & 1 Los Alamos National Laboratory & 013 & 013 & 01 & sox & 1 & & & NO EQUIPMENT & A \\
\hline 028 & 0001 & 2001 & 1 Los Alamos National Laboratory & 026 & 026 & 01 & PM10 & 92 & & & water spray & A \\
\hline 028 & 0001 & 2001 & 1 Los Alamos National Laboratory & 026 & 026 & 01 & PT & 92 & & & water spray & A \\
\hline 028 & 0001 & 2001 & 1 Los Alamos National Laboratory & 027 & 027 & 01 & PM10 & 99 & & & cyclone and baghouse & A \\
\hline 028 & 0001 & 2001 & 1 Los Alamos National Laboratory & 027 & 027 & 01 & PT & 99 & & & cyclone and baghouse & A \\
\hline
\end{tabular}


LANL Emission Inventory 2001, Stack Parameters

\begin{tabular}{|c|c|c|c|c|c|c|c|c|c|c|c|}
\hline $\begin{array}{l}\text { County } \\
\text { FIPs } \\
\text { Code }\end{array}$ & $\begin{array}{c}\text { AFS/NEDS } \\
\text { Plant ID }\end{array}$ & $\begin{array}{c}\text { Inventory } \\
\text { Year } \\
\text { (YYYY) }\end{array}$ & Company Name & Description & $\begin{array}{l}\text { AlRS } \\
\text { Stack ID }\end{array}$ & $\begin{array}{c}\text { State } \\
\text { Local } \\
\text { Stack ID }\end{array}$ & $\begin{array}{c}\text { Stack } \\
\text { Height }\end{array}$ & $\begin{array}{c}\text { Stack } \\
\text { Diameter }\end{array}$ & $\begin{array}{l}\text { Exit Gas } \\
\text { Temperature }\end{array}$ & $\begin{array}{l}\text { Exit Gas } \\
\text { Velocity }\end{array}$ & strClass \\
\hline 028 & 0001 & 2001 & Los Alamos National Laboratory & BE MACHINING TA-3 BLDG 39 & 001 & 001 & 54 & 0.9 & 70 & $38 \mathrm{~A}$ & A \\
\hline 028 & 0001 & 2001 & I Los Alamos National Laboratory & 210E6BTU/HR TA3-22 BLRS (3) & 002 & 002 & 68 & 7.7 & 416 & $12 \mathrm{~A}$ & \\
\hline 028 & 0001 & 2001 & Los Alamos National Laboratory & TA16 BOILERS (3) & 003 & 003 & 65 & 5 & 0 & $0 \mathrm{~A}$ & A \\
\hline 028 & 0001 & 2001 & Los Alamos National Laboratory & (3) & 004 & 004 & 41 & 2 & 68 & $13 \mathrm{~A}$ & \\
\hline 028 & 0001 & 2001 & Los Alamos National Laboratory & TD SITE BOILER NOT BUILT & 005 & 005 & 0 & 0 & 0 & $0 \mathrm{~A}$ & A \\
\hline 028 & 0001 & 2001 & Los Alamos National Laboratory & BE MACHINING TA35 BLDG213 & 006 & 006 & 71 & 1 & 70 & $38 \mathrm{~A}$ & \\
\hline 028 & 0001 & 2001 & Los Alamos National Laboratory & BE MACHINING TA3 BLDG 141 & 007 & 007 & 50 & 5 & 70 & $47 \mathrm{~A}$ & \\
\hline 028 & 0001 & 2001 & Los Alamos National Laboratory & BE MACHINING TA3 BLDG 102 & 008 & 008 & 45 & 3 & 70 & $19 \mathrm{~A}$ & \\
\hline 028 & 0001 & 2001 & Los Alamos National Laboratory & BE SHOP TA3-35 NOT BUILT & 009 & 009 & 0 & 0 & 0 & $0 \mathrm{~A}$ & A \\
\hline 028 & 0001 & 2001 & Los Alamos National Laboratory & BE CUTTING \& BEAD DRESSING TA-55-4 & 010 & 010 & 32 & 3.6 & 77 & $30 \mathrm{~A}$ & \\
\hline 028 & 0001 & 2001 & Los Alamos National Laboratory & STACK & 011 & 011 & 49 & 3.6 & 77 & $39 \mathrm{~A}$ & \\
\hline 028 & 0001 & 2001 & Los Alamos National Laboratory & ASPHALT PLANT TA-3-73 & 013 & 013 & 30 & 4.5 & 130 & $27 \mathrm{~A}$ & \\
\hline 028 & 0001 & 2001 & Los Alamos National Laboratory & CAT HCR-TA-SI PUMP ENGINE & 014 & 014 & 17 & 0.83 & 977 & $75 \mathrm{~A}$ & \\
\hline 028 & 0001 & 2001 & I Los Alamos National Laboratory & Boiler (TA-48-1) BS-1 & 015 & 015 & 50 & 2.3 & 300 & $10 \mathrm{~A}$ & \\
\hline 028 & 0001 & 2001 & Los Alamos National Laboratory & Boiler (TA-48-1) BS-2 & 016 & 016 & 50 & 2.3 & 300 & $10 \mathrm{~A}$ & \\
\hline 028 & 0001 & 2001 & Los Alamos National Laboratory & Boiler (TA-48-1) BS-6 & 017 & 017 & 50 & 2.3 & 300 & $13 \mathrm{~A}$ & \\
\hline 028 & 0001 & 2001 & Los Alamos National Laboratory & Boiler (TA-53-365) BHW-1 & 018 & 018 & 22 & 1.5 & 300 & $32 \mathrm{~A}$ & \\
\hline 028 & 0001 & 2001 & Los Alamos National Laboratory & Boiler (TA-53-365) BHW-2 & 019 & 019 & 22 & 1.5 & 300 & $32 \mathrm{~A}$ & \\
\hline 028 & 0001 & 2001 & Los Alamos National Laboratory & Boiler (TA-59-1) BHW-1 & 020 & 020 & 55 & 1.7 & 300 & $19 \mathrm{~A}$ & \\
\hline 028 & 0001 & 2001 & Los Alamos National Laboratory & Boiler (TA-59-1) BHW-2 & 021 & 021 & 55 & 1.7 & 300 & $19 \mathrm{~A}$ & \\
\hline 028 & 0001 & 2001 & I Los Alamos National Laboratory & Boiler (TA-55-6) BHW-1 & 022 & 022 & 30 & 1.8 & 222 & $24 \mathrm{~A}$ & \\
\hline 028 & 0001 & 2001 & Los Alamos National Laboratory & Boiler (TA-55-6) BHW-2 & 023 & 023 & 30 & 2 & 333 & $29 \mathrm{~A}$ & \\
\hline 028 & 0001 & 2001 & I Los Alamos National Laboratory & Boiler\&backup, Plant-5 (TA-16-1485) & 024 & 024 & 21 & 1.5 & 341 & $22 \mathrm{~A}$ & \\
\hline 028 & 0001 & 2001 & Los Alamos National Laboratory & Boiler and Backup, Plant 6, (TA-16-1485) & 025 & 025 & 19 & 1.8 & 341 & $14 \mathrm{~A}$ & \\
\hline 028 & 0001 & 2001 & Los Alamos National Laboratory & Rock Crusher & 026 & 026 & 3 & 3 & 70 & $0.01 \mathrm{~A}$ & \\
\hline 028 & 0001 & 2001 & Los Alamos National Laboratory & $($ TA-52-11) & 027 & 027 & 26 & 1 & 70 & $29 \mathrm{~A}$ & \\
\hline 028 & 0001 & 2001 & Los Alamos National Laboratory & Degreaser - cold ultrasonic bath TA-55-4 & 028 & 028 & 32 & 3.6 & 77 & $30 \mathrm{~A}$ & \\
\hline 028 & 0001 & 2001 & Los Alamos National Laboratory & Degreaser - cold ultrasonic bath TA-46-24 & 029 & 029 & 32 & 1 & 70 & $2.6 \mathrm{~A}$ & \\
\hline 028 & 0001 & 2001 & I Los Alamos National Laboratory & Degreaser - inhouse cold batch TA-46-24 & 030 & 030 & 32 & 1 & 70 & $2.6 \mathrm{~A}$ & \\
\hline 028 & 0001 & 2001 & Los Alamos National Laboratory & R \& D activities - Labwide & 031 & 031 & 0 & 0 & 0 & $0 A$ & A \\
\hline 028 & 0001 & 2001 & Los Alamos National Laboratory & Edgemoor Iron Works Boiler & 032 & 001 & 68 & 7.7 & 416 & $29 \mathrm{~A}$ & \\
\hline 028 & 0001 & 2001 & I Los Alamos National Laboratory & Edgemoor Iron Works Boiler & 033 & 001 & 68 & 7.7 & 416 & $29 \mathrm{~A}$ & \\
\hline 028 & 0001 & 2001 & Los Alamos National Laboratory & Edgemoor Iron Works Boiler & 034 & 001 & 68 & 7.7 & 416 & $29 \mathrm{~A}$ & \\
\hline 028 & 0001 & 2001 & Los Alamos National Laboratory & Sellers boiler TA-55-6, BHW-1B & 037 & BWH-1B & 30 & 2 & 334 & $7.8 \mathrm{~A}$ & \\
\hline 028 & 0001 & 2001 & I Los Alamos National Laboratory & Sellers boiler TA-55-6, BHW-2B & 038 & BWH-2B & 30 & 2 & 334 & $7.8 \mathrm{~A}$ & \\
\hline 028 & 0001 & 2001 & Los Alamos National Laboratory & Air Curtain Destructor S-127 & New-1 & New-1 & 10.2 & 16.9 & 2500 & $1.3 \mathrm{~A}$ & \\
\hline 028 & 0001 & 2001 & Los Alamos National Laboratory & Air Curtain Destructor T-350-1 & New-2 & New-2 & 0 & 24.6 & 2500 & $0.7 \mathrm{~A}$ & \\
\hline 028 & 0001 & 2001 & Los Alamos National Laboratory & Air Curtain Destructor T-350-2 & New-3 & New-3 & 0 & 24.6 & 2500 & $0.7 \mathrm{~A}$ & \\
\hline
\end{tabular}


LANL Emission Inventory 2001

Point Source Actual Emissions

\begin{tabular}{|c|c|c|c|c|c|c|c|c|}
\hline $\begin{array}{c}\text { County } \\
\text { FIPs } \\
\text { Code }\end{array}$ & $\begin{array}{c}\text { AFS/NEDS } \\
\text { Plant ID }\end{array}$ & $\begin{array}{c}\text { Inventory } \\
\text { Year } \\
\text { (YYYY) }\end{array}$ & Company Name & \begin{tabular}{|l|} 
AIRS \\
Point ID
\end{tabular} & \begin{tabular}{|c} 
AIRS \\
Stack \\
ID
\end{tabular} & $\begin{array}{l}\text { Pollutant } \\
\text { Code }\end{array}$ & \begin{tabular}{|c|}
2001 Actual \\
Emissions
\end{tabular} & $\begin{array}{c}\text { Emission } \\
\text { Unit } \\
\text { Numerator }\end{array}$ \\
\hline 028 & 0001 & 2001 & 1 Los Alamos National Laboratory & 001 & 001 & $\mathrm{BE}$ & & TY \\
\hline 028 & 0001 & 2001 & 1 Los Alamos National Laboratory & 001 & 001 & PT & & TY \\
\hline 028 & 0001 & 2001 & 1 Los Alamos National Laboratory & 002 & 002 & $\mathrm{co}$ & 81.3 & \\
\hline 028 & 0001 & 2001 & 1 Los Alamos National Laboratory & 002 & 002 & $\mathrm{NO} 2$ & 99.6 & \\
\hline 028 & 0001 & 2001 & 1 Los Alamos National Laboratory & 002 & 002 & PM10 & 15.7 & \\
\hline 028 & 0001 & 2001 & 1 Los Alamos National Laboratory & 002 & 002 & PT & 15.7 & TY \\
\hline 028 & 0001 & 2001 & 1 Los Alamos National Laboratory & 002 & 002 & $\mathrm{SO} 2$ & & TY \\
\hline 028 & 0001 & 2001 & 1 Los Alamos National Laboratory & 002 & 002 & VOC & & TY \\
\hline 028 & 0001 & 2001 & 1 Los Alamos National Laboratory & 004 & 004 & $\mathrm{CO}$ & 1.55 & TY \\
\hline 028 & 0001 & 2001 & 1 Los Alamos National Laboratory & 004 & 004 & NO2 & 1.85 & TY \\
\hline 028 & 0001 & 2001 & 1 Los Alamos National Laboratory & 004 & 004 & PM10 & 0.14 & TY \\
\hline 028 & 0001 & 2001 & 1 Los Alamos National Laboratory & 004 & 004 & PT & 0.14 & TY \\
\hline 028 & 0001 & 2001 & 1 Los Alamos National Laboratory & 004 & 004 & SOx & 0.01 & TY \\
\hline 028 & 0001 & 2001 & 1 Los Alamos National Laboratory & 004 & 004 & VOC & & TY \\
\hline 028 & 0001 & 2001 & 1 Los Alamos National Laboratory & 005 & 005 & $\mathrm{CO}$ & & TY \\
\hline 028 & 0001 & 2001 & 1 Los Alamos National Laboratory & 005 & 005 & $\mathrm{NO} 2$ & & TY \\
\hline 028 & 0001 & 2001 & 1 Los Alamos National Laboratory & 005 & 005 & PT & & TY \\
\hline 028 & 0001 & 2001 & 1 Los Alamos National Laboratory & 005 & 005 & VOC & & TY \\
\hline 028 & 0001 & 2001 & 1 Los Alamos National Laboratory & 006 & 006 & $\mathrm{BE}$ & 0.0000004 & TY \\
\hline 028 & 0001 & 2001 & 1 Los Alamos National Laboratory & 006 & 006 & PT & 0.0000004 & TY \\
\hline 028 & 0001 & 2001 & 1 Los Alamos National Laboratory & 007 & 007 & $\mathrm{BE}$ & 0.000004 & TY \\
\hline 028 & 0001 & 2001 & 1 Los Alamos National Laboratory & 007 & 007 & PT & 0.000004 & TY \\
\hline 028 & 0001 & 2001 & 1 Los Alamos National Laboratory & 008 & 008 & $\mathrm{BE}$ & & TY \\
\hline 028 & 0001 & 2001 & 1 Los Alamos National Laboratory & 008 & 008 & PT & & TY \\
\hline 028 & 0001 & 2001 & 1 Los Alamos National Laboratory & 009 & 009 & $\mathrm{BE}$ & & TY \\
\hline 028 & 0001 & 2001 & 1 Los Alamos National Laboratory & 009 & 009 & PT & & TY \\
\hline 028 & 0001 & 2001 & 1 Los Alamos National Laboratory & 010 & 010 & AL-PT & 0.000002 & TY \\
\hline 028 & 0001 & 2001 & 1 Los Alamos National Laboratory & 010 & 010 & $\mathrm{BE}$ & 0.000002 & TY \\
\hline 028 & 0001 & 2001 & 1 Los Alamos National Laboratory & 011 & 011 & AL-PT & 0.0000015 & TY \\
\hline 028 & 0001 & 2001 & 1 Los Alamos National Laboratory & 011 & 011 & BE & 0.0000015 & TY \\
\hline 028 & 0001 & 2001 & 1 Los Alamos National Laboratory & 013 & 013 & $\mathrm{CO}$ & 0.52 & TY \\
\hline 028 & 0001 & 2001 & 1 Los Alamos National Laboratory & 013 & 013 & $\mathrm{NO} 2$ & 0.03 & TY \\
\hline 028 & 0001 & 2001 & 1 Los Alamos National Laboratory & 013 & 013 & PM10 & 0.09 & TY \\
\hline 028 & 0001 & 2001 & 1 Los Alamos National Laboratory & 013 & 013 & PT & 0.09 & TY \\
\hline 028 & 0001 & 2001 & 1 Los Alamos National Laboratory & 013 & 013 & sox & 0.006 & TY \\
\hline 028 & 0001 & 2001 & 1 Los Alamos National Laboratory & 013 & 013 & VOC & 0.01 & TY \\
\hline
\end{tabular}


LANL Emission Inventory 2001

Point Source Actual Emissions

\begin{tabular}{|c|c|c|c|c|c|c|}
\hline 028 & 0001 & 2001 Los Alamos National Laboratory & 014 & 014 & $\mathrm{CO}$ & $3.01 \mathrm{TY}$ \\
\hline 028 & 0001 & 2001 Los Alamos National Laboratory & 014 & 014 & NO2 & $9.41 \mathrm{TY}$ \\
\hline 028 & 0001 & 2001 Los Alamos National Laboratory & 014 & 014 & PM10 & $0.06 \mathrm{TY}$ \\
\hline 028 & 0001 & 2001 Los Alamos National Laboratory & 014 & 014 & PT & $0.06 \mathrm{TY}$ \\
\hline 028 & 0001 & 2001 Los Alamos National Laboratory & 014 & 014 & sox & $0.004 \mathrm{TY}$ \\
\hline 028 & 0001 & 2001 Los Alamos National Laboratory & 014 & 014 & VOC & $0.19 \mathrm{TY}$ \\
\hline 028 & 0001 & 2001 Los Alamos National Laboratory & 015 & 015 & $\mathrm{CO}$ & $0.38 \mathrm{TY}$ \\
\hline 028 & 0001 & 2001 Los Alamos National Laboratory & 015 & 015 & NO2 & $0.45 \mathrm{TY}$ \\
\hline 028 & 0001 & 2001 Los Alamos National Laboratory & 015 & 015 & PM10 & $0.03 \mathrm{TY}$ \\
\hline 028 & 0001 & 2001 Los Alamos National Laboratory & 015 & 015 & PT & $0.03 \mathrm{TY}$ \\
\hline 028 & 0001 & 2001 Los Alamos National Laboratory & 015 & 015 & sox & 0.003 TY \\
\hline 028 & 0001 & 2001 Los Alamos National Laboratory & 015 & 015 & VOC & $0.02 \mathrm{TY}$ \\
\hline 028 & 0001 & 2001 Los Alamos National Laboratory & 016 & 016 & $\mathrm{CO}$ & $0.38 \mathrm{TY}$ \\
\hline 028 & 0001 & 2001 Los Alamos National Laboratory & 016 & 016 & NO2 & $0.45 \mathrm{TY}$ \\
\hline 028 & 0001 & 2001 Los Alamos National Laboratory & 016 & 016 & PM10 & $0.03 \mathrm{TY}$ \\
\hline 028 & 0001 & 2001 Los Alamos National Laboratory & 016 & 016 & PT & $0.03 \mathrm{TY}$ \\
\hline 028 & 0001 & 2001 Los Alamos National Laboratory & 016 & 016 & sox & $0.003 \mathrm{TY}$ \\
\hline 028 & 0001 & 2001 Los Alamos National Laboratory & 016 & 016 & VOC & $0.02 \mathrm{TY}$ \\
\hline 028 & 0001 & 2001 Los Alamos National Laboratory & 017 & 017 & $\mathrm{CO}$ & $0.5 \mathrm{TY}$ \\
\hline 028 & 0001 & 2001 Los Alamos National Laboratory & 017 & 017 & NO2 & $0.6 \mathrm{TY}$ \\
\hline 028 & 0001 & 2001 Los Alamos National Laboratory & 017 & 017 & PM10 & $0.05 \mathrm{TY}$ \\
\hline 028 & 0001 & 2001 Los Alamos National Laboratory & 017 & 017 & PT & $0.05 \mathrm{TY}$ \\
\hline 028 & 0001 & 2001 Los Alamos National Laboratory & 017 & 017 & sox & $0.004 \mathrm{TY}$ \\
\hline 028 & 0001 & 2001 Los Alamos National Laboratory & 017 & 017 & VOC & $0.03 \mathrm{TY}$ \\
\hline 028 & 0001 & 2001 Los Alamos National Laboratory & 018 & 018 & $\mathrm{CO}$ & $0.5 \mathrm{TY}$ \\
\hline 028 & 0001 & 2001 Los Alamos National Laboratory & 018 & 018 & NO2 & $0.6 \mathrm{TY}$ \\
\hline 028 & 0001 & 2001 Los Alamos National Laboratory & 018 & 018 & PM10 & $0.05 \mathrm{TY}$ \\
\hline 028 & 0001 & 2001 Los Alamos National Laboratory & 018 & 018 & PT & $0.05 \mathrm{TY}$ \\
\hline 028 & 0001 & 2001 Los Alamos National Laboratory & 018 & 018 & sox & $0.004 \mathrm{TY}$ \\
\hline 028 & 0001 & 2001 Los Alamos National Laboratory & 018 & 018 & VOC & $0.03 \mathrm{TY}$ \\
\hline 028 & 0001 & 2001 Los Alamos National Laboratory & 019 & 019 & $\mathrm{CO}$ & $0.5 \mathrm{TY}$ \\
\hline 028 & 0001 & 2001 Los Alamos National Laboratory & 019 & 019 & $\mathrm{NO} 2$ & $0.6 \mathrm{TY}$ \\
\hline 028 & 0001 & 2001 Los Alamos National Laboratory & 019 & 019 & PM10 & $0.05 \mathrm{TY}$ \\
\hline 028 & 0001 & 2001 Los Alamos National Laboratory & 019 & 019 & PT & $0.05 \mathrm{TY}$ \\
\hline 028 & 0001 & 2001 Los Alamos National Laboratory & 019 & 019 & SOx & $0.004 \mathrm{TY}$ \\
\hline 028 & 0001 & 2001 Los Alamos National Laboratory & 019 & 019 & VOC & $0.03 \mathrm{TY}$ \\
\hline 028 & 0001 & 2001 Los Alamos National Laboratory & 020 & 020 & $\mathrm{CO}$ & $0.38 \mathrm{TY}$ \\
\hline 028 & 0001 & 2001 Los Alamos National Laboratory & 020 & 020 & $\mathrm{NO} 2$ & $0.45 \mathrm{TY}$ \\
\hline
\end{tabular}


LANL Emission Inventory 2001

Point Source Actual Emissions

\begin{tabular}{|c|c|c|c|c|c|c|}
\hline 028 & 0001 & 2001 Los Alamos National Laboratory & 020 & 020 & PM10 & $0.03 \mathrm{TY}$ \\
\hline 028 & 0001 & 2001 Los Alamos National Laboratory & 020 & 020 & PT & $0.03 \mathrm{TY}$ \\
\hline 028 & 0001 & 2001 Los Alamos National Laboratory & 020 & 020 & sox & $0.003 \mathrm{TY}$ \\
\hline 028 & 0001 & 2001 Los Alamos National Laboratory & 020 & 020 & VOC & $0.02 \mathrm{TY}$ \\
\hline 028 & 0001 & 2001 Los Alamos National Laboratory & 021 & 021 & $\mathrm{CO}$ & $0.38 \mathrm{TY}$ \\
\hline 028 & 0001 & 2001 Los Alamos National Laboratory & 021 & 021 & NO2 & $0.45 \mathrm{TY}$ \\
\hline 028 & 0001 & 2001 Los Alamos National Laboratory & 021 & 021 & PM10 & $0.03 \mathrm{TY}$ \\
\hline 028 & 0001 & 2001 Los Alamos National Laboratory & 021 & 021 & PT & $0.03 \mathrm{TY}$ \\
\hline 028 & 0001 & 2001 Los Alamos National Laboratory & 021 & 021 & sox & 0.003 TY \\
\hline 028 & 0001 & 2001 Los Alamos National Laboratory & 021 & 021 & VOC & $0.02 \mathrm{TY}$ \\
\hline 028 & 0001 & 2001 Los Alamos National Laboratory & 022 & 022 & $\mathrm{CO}$ & $0 \mathrm{TY}$ \\
\hline 028 & 0001 & 2001 Los Alamos National Laboratory & 022 & 022 & $\mathrm{NO} 2$ & $0 \widehat{T Y}$ \\
\hline 028 & 0001 & 2001 Los Alamos National Laboratory & 022 & 022 & PM10 & $0 \mathrm{TY}$ \\
\hline 028 & 0001 & 2001 Los Alamos National Laboratory & 022 & 022 & PT & 0 TY \\
\hline 028 & 0001 & 2001 Los Alamos National Laboratory & 022 & 022 & sox & $0 \mathrm{TY}$ \\
\hline 028 & 0001 & 2001 Los Alamos National Laboratory & 022 & 022 & VOC & $0 \mathrm{TY}$ \\
\hline 028 & 0001 & 2001 Los Alamos National Laboratory & 023 & 023 & $\mathrm{CO}$ & $1.1 \mathrm{TY}$ \\
\hline 028 & 0001 & 2001 Los Alamos National Laboratory & 023 & 023 & $\mathrm{NO} 2$ & $0.9 \mathrm{TY}$ \\
\hline 028 & 0001 & 2001 Los Alamos National Laboratory & 023 & 023 & PM10 & $0.03 \mathrm{TY}$ \\
\hline 028 & 0001 & 2001 Los Alamos National Laboratory & 023 & 023 & PT & $0.03 \mathrm{TY}$ \\
\hline 028 & 0001 & 2001 Los Alamos National Laboratory & 023 & 023 & sox & 0.002 TY \\
\hline 028 & 0001 & 2001 Los Alamos National Laboratory & 023 & 023 & VOC & $0.02 \mathrm{TY}$ \\
\hline 028 & 0001 & 2001 Los Alamos National Laboratory & 024 & 024 & $\mathrm{CO}$ & $0.26 \mathrm{TY}$ \\
\hline 028 & 0001 & 2001 Los Alamos National Laboratory & 024 & 024 & $\mathrm{NO} 2$ & $0.26 \mathrm{TY}$ \\
\hline 028 & 0001 & 2001 Los Alamos National Laboratory & 024 & 024 & PM10 & $0.05 \mathrm{TY}$ \\
\hline 028 & 0001 & 2001 Los Alamos National Laboratory & 024 & 024 & PT & $0.05 \mathrm{TY}$ \\
\hline 028 & 0001 & 2001 Los Alamos National Laboratory & 024 & 024 & sox & $0.004 \mathrm{TY}$ \\
\hline 028 & 0001 & 2001 Los Alamos National Laboratory & 024 & 024 & VOC & $0.04 \mathrm{TY}$ \\
\hline 028 & 0001 & 2001 Los Alamos National Laboratory & 025 & 025 & $\mathrm{CO}$ & 0 TY \\
\hline 028 & 0001 & 2001 Los Alamos National Laboratory & 025 & 025 & $\mathrm{NO} 2$ & $0 \mathrm{TY}$ \\
\hline 028 & 0001 & 2001 Los Alamos National Laboratory & 025 & 025 & PM10 & 0 TY \\
\hline 028 & 0001 & 2001 Los Alamos National Laboratory & 025 & 025 & PT & $0 \mathrm{TY}$ \\
\hline 028 & 0001 & 2001 Los Alamos National Laboratory & 025 & 025 & sox & 0 TY \\
\hline 028 & 0001 & 2001 Los Alamos National Laboratory & 025 & 025 & VOC & $0 \mathrm{TY}$ \\
\hline 028 & 0001 & 2001 Los Alamos National Laboratory & 026 & 026 & $\mathrm{co}$ & 0 TY \\
\hline 028 & 0001 & 2001 Los Alamos National Laboratory & 026 & 026 & $\mathrm{NO} 2$ & $0 \mathrm{TY}$ \\
\hline 028 & 0001 & 2001 Los Alamos National Laboratory & 026 & 026 & PM10 & $0 \mathrm{TY}$ \\
\hline 028 & 0001 & 2001 Los Alamos National Laboratory & 026 & 026 & PT & 0 TY \\
\hline
\end{tabular}


LANL Emission Inventory 2001

Point Source Actual Emissions

\begin{tabular}{|c|c|c|c|c|c|c|c|}
\hline 028 & 0001 & 2001 Los Alamos National Laboratory & 026 & 026 & sox & $0 \mathrm{TY}$ & \\
\hline 028 & 0001 & 2001 Los Alamos National Laboratory & 026 & 026 & VOC & $0 \mathrm{TY}$ & \\
\hline 028 & 0001 & 2001 Los Alamos National Laboratory & 027 & 027 & PM10 & $0.0007 \mathrm{TY}$ & \\
\hline 028 & 0001 & 2001 Los Alamos National Laboratory & 027 & 027 & PT & $0.0007 \mathrm{TY}$ & \\
\hline 028 & 0001 & 2001 Los Alamos National Laboratory & 028 & 028 & 3CLET & 0.014 TY & \\
\hline 028 & 0001 & 2001 Los Alamos National Laboratory & 029 & 029 & 3CLET & 0 TY & \\
\hline 028 & 0001 & 2001 Los Alamos National Laboratory & 030 & 030 & 3CLET & 0 TY & \\
\hline 028 & 0001 & 2001 Los Alamos National Laboratory & 031 & 031 & VOC & 18.6 TY & \\
\hline 028 & 0001 & 2001 Los Alamos National Laboratory & 031 & 031 & THAP & 7.37 TY & \\
\hline 028 & 0001 & 2001 Los Alamos National Laboratory & 031 & 031 & $7647-01-0$ & $1.735 \mathrm{TY}$ & Hydrochloric acid \\
\hline 028 & 0001 & 2001 Los Alamos National Laboratory & 031 & 031 & $67-56-1$ & $0.910 \mathrm{TY}$ & Methanol \\
\hline 028 & 0001 & 2001 Los Alamos National Laboratory & 031 & 031 & $107-21-1$ & $0.718 \mathrm{TY}$ & Ethylene glycol \\
\hline 028 & 0001 & 2001 Los Alamos National Laboratory & 031 & 031 & $75-05-8$ & $0.663 \mathrm{TY}$ & Acetonitrile \\
\hline 028 & 0001 & 2001 Los Alamos National Laboratory & 031 & 031 & $79-01-6$ & 0.507 TY & Trichloroethylene \\
\hline 028 & 0001 & 2001 Los Alamos National Laboratory & 031 & 031 & $75-09-2$ & $0.436 \mathrm{TY}$ & Methylene chloride (Dichloromethane) \\
\hline 028 & 0001 & 2001 Los Alamos National Laboratory & 031 & 031 & $110-54-3$ & $0.398 \mathrm{TY}$ & Hexane \\
\hline 028 & 0001 & 2001 Los Alamos National Laboratory & 031 & 031 & $108-88-3$ & $0.340 \mathrm{TY}$ & Toluene \\
\hline 028 & 0001 & 2001 Los Alamos National Laboratory & 031 & 031 & 78-93-3 & 0.297 TY & Methyl ethyl ketone (2-Butanone) \\
\hline 028 & 0001 & 2001 Los Alamos National Laboratory & 031 & 031 & NA & 0.275 TY & Manganese Compounds \\
\hline 028 & 0001 & 2001 Los Alamos National Laboratory & 031 & 031 & $540-84-1$ & $0.234 \mathrm{TY}$ & 2,2,4-Trimethylpentane \\
\hline 028 & 0001 & 2001 Los Alamos National Laboratory & 031 & 031 & $74-87-3$ & $0.116 \mathrm{TY}$ & Methyl chloride (Chloromethane) \\
\hline 028 & 0001 & 2001 Los Alamos National Laboratory & 031 & 031 & $67-66-3$ & $0.094 \mathrm{TY}$ & Chloroform \\
\hline 028 & 0001 & 2001 Los Alamos National Laboratory & 031 & 031 & $7664-39-3$ & $0.094 \mathrm{TY}$ & Hydrogen fluoride (Hydrofluoric acid) \\
\hline 028 & 0001 & 2001 Los Alamos National Laboratory & 031 & 031 & $123-91-1$ & $0.087 \mathrm{TY}$ & 1,4-Dioxane (1,4-Diethyleneoxide) \\
\hline 028 & 0001 & 2001 Los Alamos National Laboratory & 031 & 031 & 1330-20-7 & 0.069 TY & Xylenes (isomers and mixture) \\
\hline 028 & 0001 & 2001 Los Alamos National Laboratory & 031 & 031 & $68-12-2$ & $0.060 \mathrm{TY}$ & Dimethyl formamide \\
\hline 028 & 0001 & 2001 Los Alamos National Laboratory & 031 & 031 & NA & $0.056 \mathrm{TY}$ & Chromium Compounds \\
\hline 028 & 0001 & 2001 Los Alamos National Laboratory & 031 & 031 & $7782-50-5$ & $0.043 \mathrm{TY}$ & Chlorine \\
\hline 028 & 0001 & 2001 Los Alamos National Laboratory & 031 & 031 & $71-55-6$ & $0.031 \mathrm{TY}$ & Methyl chloroform (1,1,1-Trichloroethane) \\
\hline 028 & 0001 & 2001 Los Alamos National Laboratory & 031 & 031 & $79-06-1$ & $0.025 \mathrm{TY}$ & Acrylamide \\
\hline 028 & 0001 & 2001 Los Alamos National Laboratory & 031 & 031 & 108-90-7 & $0.025 \mathrm{TY}$ & Chlorobenzene \\
\hline 028 & 0001 & 2001 Los Alamos National Laboratory & 031 & 031 & $100-41-4$ & $0.020 \mathrm{TY}$ & Ethyl benzene \\
\hline 028 & 0001 & 2001 Los Alamos National Laboratory & 031 & 031 & NA & $0.018 \mathrm{TY}$ & Cyanide Compounds \\
\hline 028 & 0001 & 2001 Los Alamos National Laboratory & 031 & 031 & $107-06-2$ & $0.017 \mathrm{TY}$ & Ethylene dichloride (1,2-Dichloroethane) \\
\hline 028 & 0001 & 2001 Los Alamos National Laboratory & 031 & 031 & 71-43-2 & 0.012 TY & Benzene (including benzene from gasoline) \\
\hline 028 & 0001 & 2001 Los Alamos National Laboratory & 031 & 031 & $56-23-5$ & 0.012 TY & Carbon tetrachloride \\
\hline 028 & 0001 & 2001 Los Alamos National Laboratory & 031 & 031 & NA & $0.010 \mathrm{TY}$ & Glycol ethers \\
\hline 028 & 0001 & 2001 Los Alamos National Laboratory & 031 & 031 & $100-42-5$ & $0.007 \mathrm{TY}$ & Styrene \\
\hline
\end{tabular}


LANL Emission Inventory 2001

Point Source Actual Emissions

\begin{tabular}{|c|c|c|c|c|c|c|c|}
\hline 028 & 0001 & 2001 Los Alamos National Laboratory & 031 & 031 & $123-31-9$ & $0.006 \mathrm{TY}$ & Hydroquinone \\
\hline 028 & 0001 & 2001 Los Alamos National Laboratory & 031 & 031 & NA & $0.006 \mathrm{TY}$ & Lead Compounds \\
\hline 028 & 0001 & 2001 Los Alamos National Laboratory & 031 & 031 & NA & $0.004 \mathrm{TY}$ & Mercury Compounds \\
\hline 028 & 0001 & 2001 Los Alamos National Laboratory & 031 & 031 & $1634-04-4$ & $0.004 \mathrm{TY}$ & Methyl tert butyl ether \\
\hline 028 & 0001 & 2001 Los Alamos National Laboratory & 031 & 031 & $95-47-6$ & $0.004 \mathrm{TY}$ & o-Xylenes \\
\hline 028 & 0001 & 2001 Los Alamos National Laboratory & 031 & 031 & $108-95-2$ & $0.003 \mathrm{TY}$ & Phenol \\
\hline 028 & 0001 & 2001 Los Alamos National Laboratory & 031 & 031 & $50-00-0$ & $0.003 \mathrm{TY}$ & Formaldehyde \\
\hline 028 & 0001 & 2001 Los Alamos National Laboratory & 031 & 031 & 108-10-1 & $0.003 \mathrm{TY}$ & Methyl isobutyl ketone (Hexone) \\
\hline 028 & 0001 & 2001 Los Alamos National Laboratory & 031 & 031 & NA & $0.003 \mathrm{TY}$ & Cadmium Compounds \\
\hline 028 & 0001 & 2001 Los Alamos National Laboratory & 031 & 031 & $121-44-8$ & $0.002 \mathrm{TY}$ & Triethylamine \\
\hline 028 & 0001 & 2001 Los Alamos National Laboratory & 031 & 031 & NA & $0.002 \mathrm{TY}$ & Arsenic Compounds (inorganic including arsine) \\
\hline 028 & 0001 & 2001 Los Alamos National Laboratory & 031 & 031 & NA & $0.002 \mathrm{TY}$ & Nickel Compounds \\
\hline 028 & 0001 & 2001 Los Alamos National Laboratory & 031 & 031 & $106-88-7$ & $0.002 \mathrm{TY}$ & 1,2-Epoxybutane \\
\hline 028 & 0001 & 2001 Los Alamos National Laboratory & 031 & 031 & $79-00-5$ & $0.002 \mathrm{TY}$ & 1,1,2-Trichloroethane \\
\hline 028 & 0001 & 2001 Los Alamos National Laboratory & 031 & 031 & $7550-45-0$ & $0.001 \mathrm{TY}$ & Titanium tetrachloride \\
\hline 028 & 0001 & 2001 Los Alamos National Laboratory & 031 & 031 & NA & $0.001 \mathrm{TY}$ & Cobalt Compounds \\
\hline 028 & 0001 & 2001 Los Alamos National Laboratory & 031 & 031 & 680-31-9 & $0.001 \mathrm{TY}$ & Hexamethylphosphoramide \\
\hline 028 & 0001 & 2001 Los Alamos National Laboratory & 031 & 031 & $108-38-3$ & $0.001 \mathrm{TY}$ & m-Xylenes \\
\hline 028 & 0001 & 2001 Los Alamos National Laboratory & 031 & 031 & $79-10-7$ & $0.001 \mathrm{TY}$ & Acrylic acid \\
\hline 028 & 0001 & 2001 Los Alamos National Laboratory & 031 & 031 & $106-51-4$ & $0.001 \mathrm{TY}$ & Quinone \\
\hline 028 & 0001 & 2001 Los Alamos National Laboratory & 031 & 031 & 74-88-4 & $0.001 \mathrm{TY}$ & Methyl iodide (Iodomethane) \\
\hline 028 & 0001 & 2001 Los Alamos National Laboratory & 031 & 031 & $156-62-7$ & $0.001 \mathrm{TY}$ & Calcium cyanamide \\
\hline 028 & 0001 & 2001 Los Alamos National Laboratory & 031 & 031 & $111-42-2$ & $0.001 \mathrm{TY}$ & Diethanolamine \\
\hline 028 & 0001 & 2001 Los Alamos National Laboratory & 031 & 031 & $101-68-8$ & $0.001 \mathrm{TY}$ & Methylene diphenyl diisocyanate (MDI) \\
\hline 028 & 0001 & 2001 Los Alamos National Laboratory & 031 & 031 & $85-44-9$ & $0.001 \mathrm{TY}$ & Phthalic anhydride \\
\hline 028 & 0001 & 2001 Los Alamos National Laboratory & 031 & 031 & NA & $0.001 \mathrm{TY}$ & Polycylic Organic Matter \\
\hline 028 & 0001 & 2001 Los Alamos National Laboratory & 031 & 031 & $106-42-3$ & $0.000 \mathrm{TY}$ & p-Xylenes \\
\hline 028 & 0001 & 2001 Los Alamos National Laboratory & 031 & 031 & $75-56-9$ & $0.000 \mathrm{TY}$ & Propylene oxide \\
\hline 028 & 0001 & 2001 Los Alamos National Laboratory & 031 & 031 & $79-11-8$ & $0.000 \mathrm{TY}$ & Chloroacetic acid \\
\hline 028 & 0001 & 2001 Los Alamos National Laboratory & 031 & 031 & $98-82-8$ & $0.000 \mathrm{TY}$ & Cumene \\
\hline 028 & 0001 & 2001 Los Alamos National Laboratory & 031 & 031 & $75-07-0$ & $0.000 \mathrm{TY}$ & Acetaldehyde \\
\hline 028 & 0001 & 2001 Los Alamos National Laboratory & 031 & 031 & $75-25-2$ & $0.000 \mathrm{TY}$ & Bromoform \\
\hline 028 & 0001 & 2001 Los Alamos National Laboratory & 031 & 031 & $122-66-7$ & $0.000 \mathrm{TY}$ & 1,2-Diphenylhydrazine \\
\hline 028 & 0001 & 2001 Los Alamos National Laboratory & 031 & 031 & 822-06-0 & $0.000 \mathrm{TY}$ & Hexamethylene-1,6-diisocyanate \\
\hline 028 & 0001 & 2001 Los Alamos National Laboratory & 031 & 031 & $106-44-5$ & $0.000 \mathrm{TY}$ & p-Cresol \\
\hline 028 & 0001 & 2001 Los Alamos National Laboratory & 031 & 031 & $106-50-3$ & $0.000 \mathrm{TY}$ & p-Phenylenediamine \\
\hline 028 & 0001 & 2001 Los Alamos National Laboratory & 031 & 031 & $75-55-8$ & $0.000 \mathrm{TY}$ & 1,2-Propylenimine (2-Methyl aziridine) \\
\hline 028 & 0001 & 2001 Los Alamos National Laboratory & 031 & 031 & $100-02-7$ & $0.000 \mathrm{TY}$ & 4-Nitrophenol \\
\hline
\end{tabular}


LANL Emission Inventory 2001

Point Source Actual Emissions

\begin{tabular}{|c|c|c|c|c|c|c|c|}
\hline 028 & 0001 & 2001 Los Alamos National Laboratory & 031 & 031 & $80-62-6$ & $0.000 \mathrm{TY}$ & Methyl methacrylate \\
\hline 028 & 0001 & 2001 Los Alamos National Laboratory & 031 & 031 & $62-53-3$ & $0.000 \mathrm{TY}$ & Aniline \\
\hline 028 & 0001 & 2001 Los Alamos National Laboratory & 031 & 031 & $107-30-2$ & $0.000 \mathrm{TY}$ & Chloromethyl methyl ether \\
\hline 028 & 0001 & 2001 Los Alamos National Laboratory & 031 & 031 & $51-28-5$ & $0.000 \mathrm{TY}$ & 2,4-Dinitrophenol \\
\hline 028 & 0001 & 2001 Los Alamos National Laboratory & 031 & 031 & $60-34-4$ & $0.000 \mathrm{TY}$ & Methyl hydrazine \\
\hline 028 & 0001 & 2001 Los Alamos National Laboratory & 031 & 031 & NA & $0.000 \mathrm{TY}$ & Antimony Compounds \\
\hline 028 & 0001 & 2001 Los Alamos National Laboratory & 031 & 031 & $106-99-0$ & $0.000 \mathrm{TY}$ & 1,3-Butadiene \\
\hline 028 & 0001 & 2001 Los Alamos National Laboratory & 031 & 031 & & TY & \\
\hline 028 & 0001 & 2001 Los Alamos National Laboratory & 031 & 031 & & TY & \\
\hline 028 & 0001 & 2001 Los Alamos National Laboratory & 031 & 031 & & TY & \\
\hline 028 & 0001 & 2001 Los Alamos National Laboratory & 031 & 031 & & TY & \\
\hline 028 & 0001 & 2001 Los Alamos National Laboratory & 031 & 031 & & TY & \\
\hline 028 & 0001 & 2001 Los Alamos National Laboratory & 031 & 031 & & TY & \\
\hline 028 & 0001 & 2001 Los Alamos National Laboratory & 031 & 031 & & TY & \\
\hline 028 & 0001 & 2001 Los Alamos National Laboratory & 031 & 031 & & TY & \\
\hline 028 & 0001 & 2001 Los Alamos National Laboratory & 031 & 031 & & TY & \\
\hline 028 & 0001 & 2001 Los Alamos National Laboratory & 031 & 031 & & TY & \\
\hline 028 & 0001 & 2001 Los Alamos National Laboratory & 031 & 031 & & TY & \\
\hline 028 & 0001 & 2001 Los Alamos National Laboratory & 031 & 031 & & TY & \\
\hline 028 & 0001 & 2001 Los Alamos National Laboratory & 031 & 031 & & TY & \\
\hline 028 & 0001 & 2001 Los Alamos National Laboratory & 031 & 031 & & TY & \\
\hline 028 & 0001 & 2001 Los Alamos National Laboratory & 032 & 032 & $\mathrm{CO}$ & 4.77 TY & \\
\hline 028 & 0001 & 2001 Los Alamos National Laboratory & 032 & 032 & NO2 & 19.64 TY & \\
\hline 028 & 0001 & 2001 Los Alamos National Laboratory & 032 & 032 & PM10 & $0.97 \mathrm{TY}$ & \\
\hline 028 & 0001 & 2001 Los Alamos National Laboratory & 032 & 032 & PT & $0.97 \mathrm{TY}$ & \\
\hline 028 & 0001 & 2001 Los Alamos National Laboratory & 032 & 032 & SOx & $0.52 \mathrm{TY}$ & \\
\hline 028 & 0001 & 2001 Los Alamos National Laboratory & 032 & 032 & VOC & $0.63 \mathrm{TY}$ & \\
\hline 028 & 0001 & 2001 Los Alamos National Laboratory & 033 & 033 & $\mathrm{CO}$ & $7.4 \mathrm{TY}$ & \\
\hline 028 & 0001 & 2001 Los Alamos National Laboratory & 033 & 033 & NO2 & $30.16 \mathrm{TY}$ & \\
\hline 028 & 0001 & 2001 Los Alamos National Laboratory & 033 & 033 & PM10 & $1.41 \mathrm{TY}$ & \\
\hline 028 & 0001 & 2001 Los Alamos National Laboratory & 033 & 033 & PT & $1.41 \mathrm{TY}$ & \\
\hline 028 & 0001 & 2001 Los Alamos National Laboratory & 033 & 033 & SOx & $0.11 \mathrm{TY}$ & \\
\hline 028 & 0001 & 2001 Los Alamos National Laboratory & 033 & 033 & VOC & $1.02 \mathrm{TY}$ & \\
\hline 028 & 0001 & 2001 Los Alamos National Laboratory & 034 & 034 & $\mathrm{CO}$ & $5.91 \mathrm{TY}$ & \\
\hline 028 & 0001 & 2001 Los Alamos National Laboratory & 034 & 034 & NO2 & $24.09 \mathrm{TY}$ & \\
\hline 028 & 0001 & 2001 Los Alamos National Laboratory & 034 & 034 & PM10 & $1.12 \mathrm{TY}$ & \\
\hline 028 & 0001 & 2001 Los Alamos National Laboratory & 034 & 034 & PT & 1.12 TY & \\
\hline 028 & 0001 & 2001 Los Alamos National Laboratory & 034 & 034 & SOx & $0.09 \mathrm{TY}$ & \\
\hline
\end{tabular}


LANL Emission Inventory 2001 Point Source Actual Emissions

\begin{tabular}{|c|c|c|c|c|c|c|}
\hline 028 & 0001 & 2001 Los Alamos National Laboratory & 034 & 034 & VOC & $0.81 \mathrm{TY}$ \\
\hline 028 & 0001 & 2001 Los Alamos National Laboratory & 035 & 035 & VOC & 0.007 TY \\
\hline 028 & 0001 & 2001 Los Alamos National Laboratory & 036 & 036 & Voc & $0.034 \mathrm{TY}$ \\
\hline 028 & 0001 & 2001 Los Alamos National Laboratory & 037 & 037 & CO & $0.4 \mathrm{TY}$ \\
\hline 028 & 0001 & 2001 Los Alamos National Laboratory & 037 & 037 & $\mathrm{NO} 2$ & $1.44 \mathrm{TY}$ \\
\hline 028 & 0001 & 2001 Los Alamos National Laboratory & 037 & 037 & sox & $0.01 \mathrm{TY}$ \\
\hline 028 & 0001 & 2001 Los Alamos National Laboratory & 037 & 037 & PM10 & $0.15 \mathrm{TY}$ \\
\hline 028 & 0001 & 2001 Los Alamos National Laboratory & 037 & 037 & PT & $0.15 \mathrm{TY}$ \\
\hline 028 & 0001 & 2001 Los Alamos National Laboratory & 037 & 037 & VOC & $0.06 \mathrm{TY}$ \\
\hline 028 & 0001 & 2001 Los Alamos National Laboratory & 038 & 038 & $\mathrm{CO}$ & $0.15 \mathrm{TY}$ \\
\hline 028 & 0001 & 2001 Los Alamos National Laboratory & 038 & 038 & $\mathrm{NO} 2$ & $0.54 \mathrm{TY}$ \\
\hline 028 & 0001 & 2001 Los Alamos National Laboratory & 038 & 038 & sox & 0.002 TY \\
\hline 028 & 0001 & 2001 Los Alamos National Laboratory & 038 & 038 & PM10 & $0.06 \mathrm{TY}$ \\
\hline 028 & 0001 & 2001 Los Alamos National Laboratory & 038 & 038 & PT & $0.06 \mathrm{TY}$ \\
\hline 028 & 0001 & 2001 Los Alamos National Laboratory & 038 & 038 & VOC & $0.02 \mathrm{TY}$ \\
\hline 028 & 0001 & 2001 Los Alamos National Laboratory & New-1 & New-1 & PT & $0.02 \mathrm{TY}$ \\
\hline 028 & 0001 & 2001 Los Alamos National Laboratory & New-1 & New-1 & PM10 & $0.01 \mathrm{TY}$ \\
\hline 028 & 0001 & 2001 Los Alamos National Laboratory & New-1 & New-1 & $\mathrm{NO}_{2}$ & $0.19 \mathrm{TY}$ \\
\hline 028 & 0001 & 2001 Los Alamos National Laboratory & New-1 & New-1 & sox & $0.01 \mathrm{TY}$ \\
\hline 028 & 0001 & 2001 Los Alamos National Laboratory & New-1 & New-1 & $\mathrm{CO}$ & $0.10 \mathrm{TY}$ \\
\hline 028 & 0001 & 2001 Los Alamos National Laboratory & New-1 & New-1 & VOC & $0.25 \mathrm{TY}$ \\
\hline 028 & 0001 & 2001 Los Alamos National Laboratory & New-2 & New-2 & PT & $0.62 \mathrm{TY}$ \\
\hline 028 & 0001 & 2001 Los Alamos National Laboratory & New-2 & New-2 & PM10 & $0.47 \mathrm{TY}$ \\
\hline 028 & 0001 & 2001 Los Alamos National Laboratory & New-2 & New-2 & $\mathrm{NO}_{2}$ & $0.97 \mathrm{TY}$ \\
\hline 028 & 0001 & 2001 Los Alamos National Laboratory & New-2 & New-2 & sox & $0.03 \mathrm{TY}$ \\
\hline 028 & 0001 & 2001 Los Alamos National Laboratory & New-2 & New-2 & $\mathrm{co}$ & $0.50 \mathrm{TY}$ \\
\hline 028 & 0001 & 2001 Los Alamos National Laboratory & New-2 & New-2 & VOC & 1.16 TY \\
\hline 028 & 0001 & 2001 Los Alamos National Laboratory & New-3 & New-3 & PT & $0.51 \mathrm{TY}$ \\
\hline 028 & 0001 & 2001 Los Alamos National Laboratory & New-3 & New-3 & PM10 & $0.39 \mathrm{TY}$ \\
\hline 028 & 0001 & 2001 Los Alamos National Laboratory & New-3 & New-3 & $\mathrm{NO}_{2}$ & $0.72 \mathrm{TY}$ \\
\hline 028 & 0001 & 2001 Los Alamos National Laboratory & New-3 & New-3 & sox & $0.02 \mathrm{TY}$ \\
\hline 028 & 0001 & 2001 Los Alamos National Laboratory & New-3 & New-3 & co & $0.39 \mathrm{TY}$ \\
\hline 028 & 0001 & 2001 Los Alamos National Laboratory & New-3 & New-3 & Voc & $0.95 \mathrm{TY}$ \\
\hline
\end{tabular}


LANL 2001 Emission Inventory

\section{LANL Site Totals}

\begin{tabular}{|c|c|c|c|c|c|c|c|c|c|}
\hline $\begin{array}{c}\text { County } \\
\text { FIPS }\end{array}$ & $\begin{array}{c}\text { AFS/NEDS } \\
\text { Plant ID } \\
\end{array}$ & $\begin{array}{c}\text { strCl } \\
\text { ass }\end{array}$ & $\begin{array}{c}\text { Inventory } \\
\text { Year } \\
\text { (YYYY) }\end{array}$ & Company Name & $\begin{array}{c}\text { Emission } \\
\text { Type }\end{array}$ & CAS Number & $\begin{array}{l}\text { Pollutant } \\
\text { Code }\end{array}$ & $\begin{array}{l}\text { Emission } \\
\text { Numeric } \\
\text { Value }\end{array}$ & $\begin{array}{c}\text { Emission } \\
\text { Unit } \\
\text { Numerator }\end{array}$ \\
\hline 028 & 0001 & A & 2001 & Los Alamos National Laboratory & 12 & & PM10 & \multicolumn{2}{|c|}{$5.5 \mathrm{TY}$} \\
\hline 028 & 0001 & A & 2001 & Los Alamos National Laboratory & 12 & & PT & \multicolumn{2}{|c|}{$5.5 \mathrm{TY}$} \\
\hline 028 & 0001 & A & 2001 & Los Alamos National Laboratory & 12 & & VOC & \multicolumn{2}{|c|}{$24.1 \mathrm{TY}$} \\
\hline 028 & 0001 & A & 2001 & Los Alamos National Laboratory & 12 & & THAPs & \multicolumn{2}{|c|}{ 7.4 TY } \\
\hline 028 & 0001 & A & 2001 & Los Alamos National Laboratory & 12 & 630080 & $\mathrm{CO}$ & \multicolumn{2}{|c|}{$29.1 \mathrm{TY}$} \\
\hline 028 & 0001 & A & 2001 & Los Alamos National Laboratory & 12 & 10102440 & NO2 & \multicolumn{2}{|c|}{$93.8 \mathrm{TY}$} \\
\hline 028 & 0001 & A & 2001 & Los Alamos National Laboratory & 12 & & SOx & \multicolumn{2}{|c|}{$0.82 \mathrm{TY}$} \\
\hline 028 & 0001 & A & 2001 & Los Alamos National Laboratory & 12 & 7440417 & $\mathrm{BE}$ & \multicolumn{2}{|c|}{ 9.60E-06 TY } \\
\hline 028 & 0001 & A & 2001 & Los Alamos National Laboratory & 12 & 7429905 & AL-PT & $2.05 \mathrm{E}-06$ & TY \\
\hline
\end{tabular}


This report has been reproduced directly from the best available copy. It is available electronically on the Web (http://www.doe.gov/bridge).

Copies are available for sale to U.S. Department of Energy employees and contractors from:

Office of Scientific and Technical Information P.O. Box 62

Oak Ridge, TN 37831

(865) 576-8401

Copies are available for sale to the public from: National Technical Information Service

U.S. Department of Commerce

5285 Port Royal Road

Springfield, VA 22616

(800) 553-6847 
